\title{
Adaptation of Mechanoelectrical Transduction in Hair Cells of the Bullfrog's Sacculus
}

\author{
R. A. Eatock, ${ }^{1,2}$ D. P. Corey, ${ }^{1,3, a}$ and A. J. Hudspeth ${ }^{1,4, b}$ \\ 'Division of Biology, California Institute of Technology, Pasadena, California 91125; ' $E$ aton-Peabody Laboratory of Auditory \\ Physiology, Massachusetts Eye and Ear Infirmary, Boston, Massachusetts 02114; ${ }^{3}$ Neuroscience Group, Howard Hughes \\ Medical Institute and Department of Neurology, Massachusetts General Hospital, Boston, Massachusetts 02114; and \\ ${ }^{4}$ Department of Physiology, University of California School of Medicine, San Francisco, California 94143
}

\begin{abstract}
Adaptation in a vestibular organ, the bullfrog's sacculus, was studied in vivo and in vitro. In the in vivo experiments, the discharge of primary saccular neurons and the extracellular response of saccular hair cells were recorded during steps of linear acceleration. The saccular neurons responded at the onset of the acceleration steps, then adapted fully within 10-50 msec. The extracellular (microphonic) response of the hair cells adapted with a similar time course, indicating that the primary sources of the neural adaptation are peripheral to the afferent synapse-in the hair cell, its mechanical inputs, or both. Evidence for hair cell adaptation was provided by 2 in vitro preparaiions: after excising the sacculus and removing the accessory structures, we recorded either the extracellular hair cell response to displacement of the otolithic membrane or the intracellular hair cell response to hair bundle displacement. In both cases the response to a step stimulus adapted. The adaptation involved a shift in the displacement-response curve along the displacement axis, so that the cell's operating point was reset toward the static position of its hair bundle. This displacement shift occurred in response to both depolarizing and hyperpolarizing stimuli. Its time course varied among cells, from tens to hundreds of milliseconds, and also varied with the concentration of $\mathrm{Ca}^{2+}$ bathing the apical surfaces of the hair cells. Voltageclamp experiments suggested that the displacement shift does not depend simply on ion entry through the hair cell's transduction channels and can occur at a fixed membrane potential. The possible role of the displacement-shift pro-
\end{abstract}

Received Oct. 27, 1986; revised Feb. 20, 1987; accepted Mar. 10, 1987.

This research was supported by National Institutes of Health Grants NS-13154 and NS-20429 (to A.J.H.), NS-22059 (to D.P.C.), GM-02031 and GM-07616 (to the California Institute of Technology); by fellowships from the Natural Sciences and Engineering Research Council of Canada, the Medical Research Council of Canada, and the Gordon Ross Medical Foundation (to R.A.E.); and by grants from the William Randolph Hearst Foundation, the Pew Memorial Trust, the Alfred P. Sloan Foundation, and the Howard Hughes Medical Institute. We thank Richard Jacobs for excellent and good-natured technical assistance, John Maunsell and Andy Moiseff for computer assistance, and Wendy Smith for participating in the experiments of Figures 8 and 11. We thank Aniruddha Das, Joe Howard, Walter Koroshetz, Villu Maricq, John Maunsell, Aline McKenzie, Erich Phillips, and Bill Roberts for comments on the manuscript.

Correspondence should be addressed to R. A. Eatock, Department of Physiology, University of Rochester Medical Center, Box 642, 601 Elmwood Avenue, Rochester, NY 14642.

a Present address: Neuroscience Group, Howard Hughes Medical Institute and Department of Neurology, Massachusetts General Hospital, Boston, MA 02114.

b Present address: Department of Physiology, University of California School of Medicine, San Francisco, CA 94143-0444.

Copyright (C) 1987 Society for Neuroscience $0270-6474 / 87 / 092821-16 \$ 02.00 / 0$ cess in the function of the frog's sacculus as a very sensitive vibration detector is discussed.

The term "sensory adaptation" is applied to a wide variety of phenomena. In a broad sense, it can be defined as any decrease with time in a sensory response to a constant input. Such response decays occur via diverse mechanisms, including refractoriness in spike generation, decreased synaptic gain, change in the sensitivity of a transduction process, and reduction of the input to receptor cells. Response decays during constant stimuli are often seen in afferent neurons innervating organs of the inner ear, where they are usually attributed to decay of the mechanical input to the sensory hair cells or to processes at the afferent synapse. In this paper we report a different kind of adaptation in an inner-ear organ: hair cells in the sacculus of the bullfrog adapt through a process that resets the range of scnsitivity of the mechanoelectrical transducer.

The sacculus (Figs. 1,2) is an otolithic organ. The characteristic feature of such organs is the otoconial mass, an aggregate of calcareous crystals (otoconia) within the endolymphatic chamber. An otolithic membrane couples the otoconial mass to the sensory epithelium, the macula, which comprises hair cells and supporting cells. The hair bundles of the hair cells protrude from the endolymphatic surface of the epithelium and are connected by strands to the otolithic membrane. The hair cells are innervated on their basolateral surfaces by both afferent and efferent nerve fibers. Electrophysiological studies in several species show that otolithic afferents respond to linear accelerations (for a review, see Goldberg and Fernandez, 1975). A widely accepted model of the mechanical behavior of otolithic organs is based on the observation that the otoconial mass is denser than the surrounding fluid and can move within that fluid (Young, 1969; Goldberg and Fernandez, 1975). The model proposes that when the animal undergoes linear acceleration, the position of the otoconial mass lags behind that of the surrounding fluid and tissues. The lag deflects the hair bundles, which are coupled to the otoconial mass by the otolithic membrane. Hair bundle deflection modulates the hair cell's conductance; the resulting receptor current produces a receptor potential (Hudspeth and Corey, 1977).

In this paper we show that the spike activity in primary saccular neurons adapts during a maintained linear acceleration. Such adaptation could be due to any of several mechanisms (Fig. $1 B$ ), including negative feedback mediated by efferents, spike refractoriness, synaptic adaptation, decay of the hair cell 
A

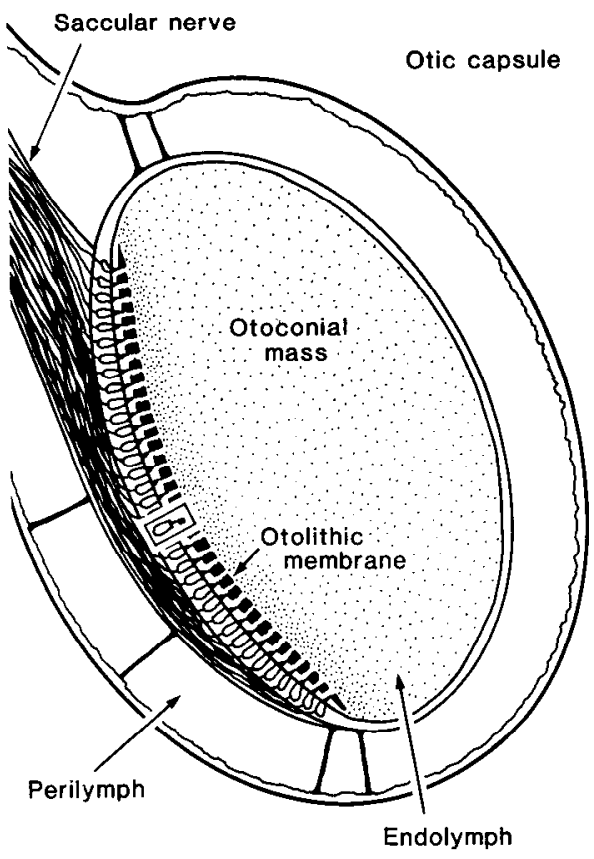

B

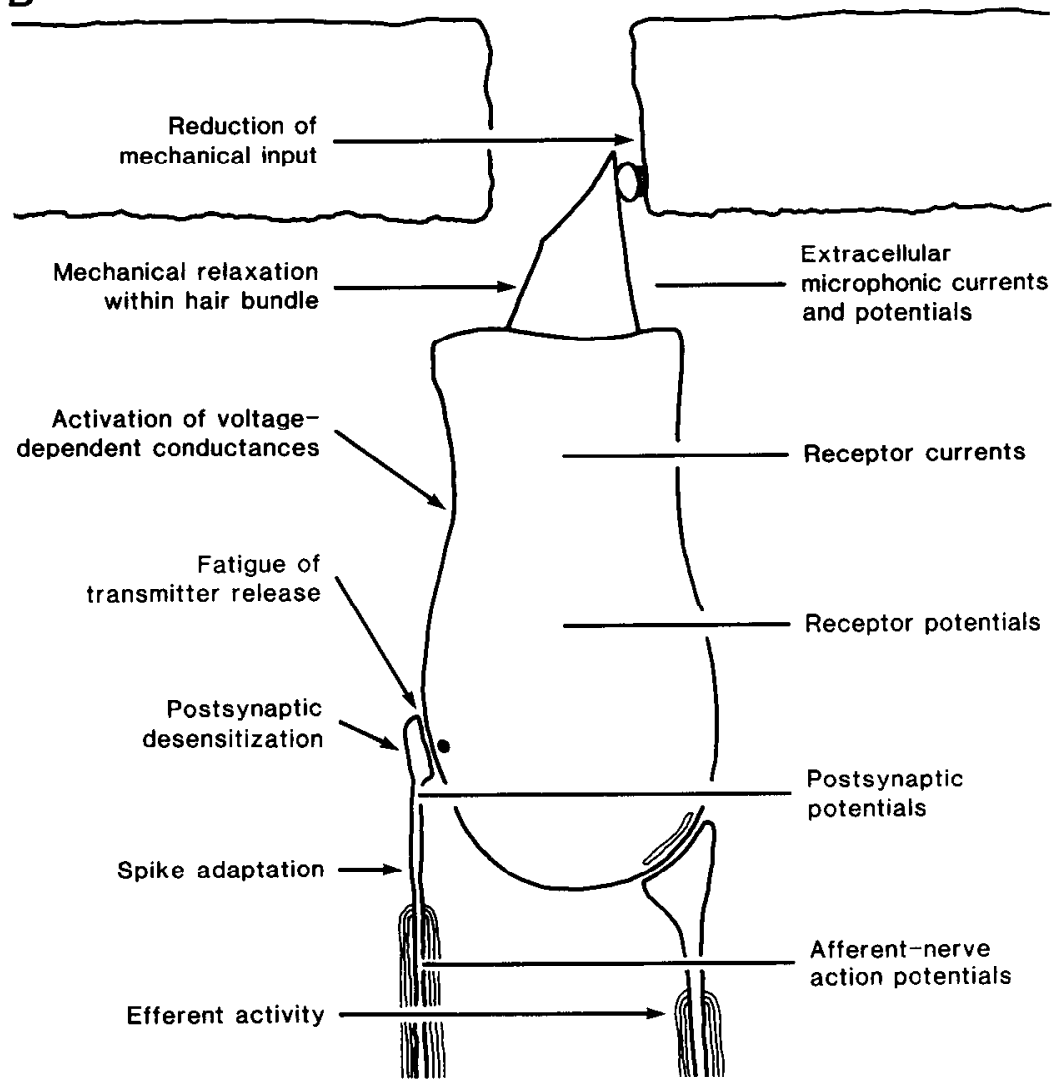

Figure 1. A, Schematic cross section through the entire sacculus. The otoconial mass is coupled to hair bundles by the perforated otolithic membrane. One of the roughly 3000 hair cells in the saccular macula is indicated by a box. $B$, Higher-magnification diagram of a hair cell innervated by an afferent and an efferent fiber. The labels to the left and right indicate, respectively, the possible sites of adaptation in this organ and the different types of recording that were made in this study.

receptor potential or receptor current, and relaxation of the mechanical input to the hair cells. We examine these possibilities by presenting data recorded from stages antecedent to spike generation: the synaptic potentials in the afferent terminals, extracellular hair cell responses (the microphonic current and microphonic potential), and intracellular hair cell responses (the receptor current and receptor potential). We show that the adaptation involves a shift of the sensitive range of the mechanoelectrical transduction process in the hair cells. Somc of thesc data have been reported in preliminary form (Eatock et al., 1979; Eatock and Hudspeth, 1981; Corey and Hudspeth, 1983a).

\section{Materials and Methods}

The experimental animals were American bullfrogs, Rana catesbeiana, weighing 75-150 gm. Unless otherwise indicated, all surgery and experiments were conducted at $20-24^{\circ} \mathrm{C}$.

In vivo experiments. Anesthetized frogs were stimulated with linear accelerations and responses were recorded at 3 locations. In 27 experiments, the extracellular voltage in the endolymphatic compartment of the sacculus was recorded. We refer to the stimulus-locked portion of this voltage as the in vivo microphonic potential, as it is comparable to microphonic potentials recorded from other hair cell organs. In 14 experiments, we recorded intra- and extracellularly from a total of 71 saccular nerve fibers near their terminals in the sensory epithelium. The occurrence of short-latency, stimulus-locked synaptic potentials in these recordings indicated that these fibers were afferent. In 14 different experiments, we recorded intra- and extracellularly from 35 neurons more proximally in the saccular nerve, near the point at which it branches from the anterior ramus of the eighth nerve. Histological examination of this region suggested that most of these recordings were from fibers, but that some may have been from cell bodies.

Before surgery, the bullfrog was anesthetized by immersion for about $30 \mathrm{~min}$ in $6 \mathrm{~mm} \mathrm{~m}$-aminobenzoic acid ethyl ester methane sulfonate (Tricaine; Calbiochem, San Diego, CA). During surgery and recording, the animal's skin was kept moist with a gauze pad soaked in the anesthetic solution. It was often necessary to supplement the anesthesia with up to $100 \mu \mathrm{l}$ of sodium pentobarbital (Nembutal; Abbott Laboratories, North Chicago, IL; $50 \mathrm{gm} /$ liter) injected intraperitoneally in aliquots no greater than $30 \mu \mathrm{l}$.

The saccular macula and the saccular nerve lie ventrally within the otic capsule and are exposed easily through the roof of the mouth. In over half of the experiments we used this ventral surgical approach and the frog remained supine during recording. To test whether saccular responses are affected by the animal's position, we used a dorsal surgical approach in 13 of the intrasaccular experiments and 9 of the nerve experiments, and recorded with the animal prone. Because the results of these experiments did not differ from those obtained with the ventral approach, we have pooled the data.

Following surgery, the frog was secured to a platform on an electromagnetic shaker (model 408; Ling Dynamic Systems, Royston, UK) and stimulated by accelerating the platform vertically. Steps of constant acceleration were obtained by driving the shaker with current steps (10$100 \mathrm{msec}$ duration) or a square-wave current input (5-30 Hz), low-passfiltered so that transitions had rise times of 3-6 msec. This produced vertical linear accelerations of the platform that were proportional to the input. A miniature piezoresistive accelerometer (model 2264-150; Endevco, San Juan Capistrano, CA) was mounted on the platform to monitor acceleration and provide feedback to the shaker driver. Stimulus amplitudes, superimposed on the steady acceleration due to gravity, were between 0.1 and $1 \mathrm{~m} / \mathrm{sec}^{2}$. Background acceleration noise had a peak-to-peak magnitude of approximately $30 \mathrm{~mm} / \mathrm{sec}^{2}$, with occasional 



Figure 2. A, Scanning electron micrograph demonstrating the attachment of a saccular hair bundle to the otolithic membrane. Each hair bundle $(H B)$, which comprises many stereocilia and one kinocilium, protrudes into a canal in the overlying otolithic membrane $(O M)$. The bulbous tip of the kinocilium (arrowhead) is linked to the otolithic membrane. The arrow indicates the positive stimulus direction. Scale bar, $1 \mu \mathrm{m}$. $B$, Transmission electron micrograph of a section through the distal portion of a hair bundle. The kinociliary bulb $(K B)$ is connected to the otolithic membrane $(O M)$ by radial fibers, and to the adjacent stereocilia by dense, punctate contacts (arrowhead). Scale bar, $200 \mathrm{~nm}$.

larger transients. The data were averaged to increase the signal-to-noise ratio.

Recording electrodes were glass micropipettes filled with $3 \mathrm{M} \mathrm{KCl}$, with resistances of $40-100 \mathrm{M} \Omega$ for recording from neurons and $10-40$ $\mathrm{M} \Omega$ for recording microphonic potentials. The electrode holder was attached to the platform on the shaker and the microelectrodes were advanced with a hydraulic microdrive. The ground electrode was a chlorided silver wire inserted into tissue near the recording site.

In the experiments in which intracellular recordings were made near the afferent terminals of saccular neurons, tetrodotoxin (Sigma Chemical Co., St. Louis, MO), at a concentration of $30 \mathrm{~nm}$ in artificial normal perilymph (Table 1) was applied to reduce spike activity and reveal graded postsynaptic potentials. After isolating a fiber and recording its spike activity in response to acceleration, we applied $50 \mu \mathrm{l}$ aliquots of the tetrodotoxin solution to the surface of the nerve in the vicinity of the microelectrode. The tetrodotoxin temporarily reduced or abolished spiking.

In the experiments in which the microphonic potential was recorded, some of the bone surrounding the otoconial mass was removed to allow passage of the microelectrode. In many experiments, after the microelectrode was advanced in the otoconial mass and responses were de- tected, agar (3\% in normal perilymph) was added to cover the exposed surface of the otoconial mass and the electrode shank. This procedure stabilized the electrode mechanically and partially compensated for the effects that opening the bone had on the motion of the otoconial mass.

Recorded potentials were amplified by a high-impedance DC preamplifer (model P18; Grass Instruments, Quincy, MA). In the nerve experiments, the amplified potentials were stored with an FM tape recorder (model 3968A; Hewlett-Packard, San Diego, CA; passband DC-1.25 $\mathrm{kHz}$ ). The stored data were analyzed off-line with a computer. Intracellular postsynaptic potentials were averaged and peristimulus time (PST) histograms were generated from the spike data. The microphonic potentials were computer-averaged on-line. The bin width of the PST histograms, and the resolution of the concurrent averages of the acceleration stimulus (the accelerometer output), were $1 \mathrm{msec}$. The resolution of the averages of microphonic and postsynaptic potentials varied from $50 \mu \mathrm{sec}$ to $1.1 \mathrm{msec}$, depending on the duration of the averaging cycle.

In vitro microphonic current. In separate experiments, we used the in vitro epithelial preparation of the bullfrog sacculus (Corey and Hudspeth, 1979b, 1983a). The saccular macula was dissected from the frog and positioned across a hole separating 2 chambers, which were separately and continuously perfused during an experiment. The saline in

Table 1. Ionic compositions of saline solutions

\begin{tabular}{|c|c|c|c|c|c|c|}
\hline & $\mathrm{Na}^{+}$ & $\mathrm{K}^{+}$ & $\mathrm{Ca}^{2+}$ & $\mathrm{Sr}^{2+}$ & $\mathrm{Mg}^{2+}$ & $\mathrm{Cl}^{-}$ \\
\hline Normal endolymph & 2.5 & 124 & 0.26 & 0 & 0 & 127 \\
\hline $10 \mathrm{mM} \mathrm{Ca}^{2+}$ endolymph & 0 & 107 & 10 & 0 & 0 & 127 \\
\hline $1 \mathrm{mM} \mathrm{Ca}^{2+}$ endolymph & 0 & 125 & 1 & 0 & 0 & 127 \\
\hline $0.25 \mathrm{mM} \mathrm{Ca}^{2+}$ endolymph & 0 & 126.5 & 0.25 & 0 & 0 & 127 \\
\hline $0.1 \mathrm{mM} \mathrm{Ca}^{2+}$ endolymph & 0 & 126.8 & 0.1 & 0 & 0 & 127 \\
\hline $\mathrm{Sr}^{2+}$ and $\mathrm{Ca}^{2+}$ endolymph & 0 & 124 & 1 & 2 & 0 & 130 \\
\hline Normal perilymph & 119.3 & 3.6 & 1.36 & 0 & 0 & 127 \\
\hline High- $\mathrm{K}^{+}$perilymph & 108.5 & 17 & 1.36 & 0 & 0.68 & 129.6 \\
\hline $4 \mathrm{mM} \mathrm{Ca}^{2+}$ perilymph & 118.6 & 2 & 4 & 0 & 0.68 & 130 \\
\hline
\end{tabular}

All values are millimolar concentrations. Each solution also contains $3 \mathrm{~mm}$ D-glucose and $5 \mathrm{~mm}$ HEPES, pH 7.25. 


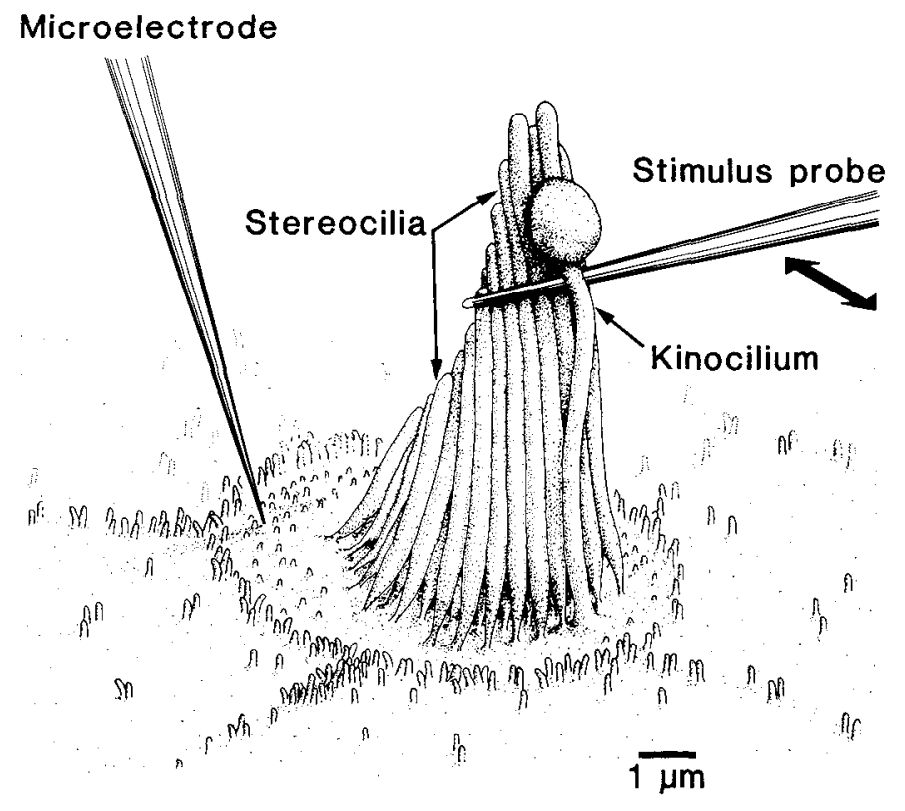

Figure 3. The arrangement for stimulating and recording receptor potentials in single hair cells. A glass stimulus probe lodged between the kinocilium and adjacent stereocilia is used to displace the bundle along its axis of morphological symmetry (arrow). Membrane potential was measured with an intracellular microelectrode. For voltage-clamp measurements of receptor current, a second, current-passing microelectrode was inserted.

the upper chamber, bathing the apical, hair-bundle-bearing surfaces of the hair cells, was either artificial normal endolymph, similar to authentic endolymph, or had an altered $\mathrm{Ca}^{2+}$ concentration (Table 1). The saline in the lower chamber, bathing the basolateral cell surfaces, was either artificial normal perilymph, similar to authentic perilymph, or had an elevated $\mathrm{K}^{+}$concentration (Table 1 ). The temperature, measured with a thermocouple positioned $1 \mathrm{~mm}$ from the tissue, was between 20 and $24^{\circ} \mathrm{C}$ unless otherwise specified.

The otolithic membrane was peeled off most of the macula, so that it remained attached only to a group of several hundred hair cells with similar orientations at the abneural periphery of the macula (Corey and Hudspeth, 1983a). These cells were stimulated by moving the otolithic membrane with a glass probe attached to a piezoelectric bimorph device that provided motion in one dimension (Corey and Hudspeth, 1980). The response was recorded as a stimulus-induced change in the current across the epithelium, while the potential across the epithelium was held at a fixed value near zero. The motion of the probe tip was parallel to the plane of the epithelium and directed along the average axis of morphological symmetry of the stimulated cells. The amplitude of probe displacement was calibrated by observing the probe tip at $1000 \times$ under a compound microscope while the bimorph was driven with a lowfrequency square wave. The time course of probe displacement was monitored optically (Corey and Hudspeth, 1980; Corey and Hudspeth, 1983a). In some experiments, the displacement of the otolithic membrane was also directly monitored by focusing the optical monitor on clumps of otoconia embedded in the membrane. Each stimulus was typically a step displacement of $100 \mathrm{msec}$ duration and $500 \mathrm{~nm}$ amplitude (the adapting step), with a superimposed test step of $5 \mathrm{msec}$ duration and variable amplitude. Displacement rise times were less than $120 \mu \mathrm{sec}$.

In vitro intracellular recording. The sacculus was excised and the otoconial mass was removed as described above. In order to expose the apical surfaces of the hair cells, the otolithic membrane was removed after treating the tissue for $1 \mathrm{hr}$ with a proteolytic enzyme, subtilopeptidase A (Sigma Chemical Co., St. Louis, MO; $30 \mathrm{mg} /$ liter in normal perilymph). The epithelium containing the macula was positioned in a $1 \mathrm{ml}$ chamber on the stage of a compound microscope (model WL; Karl Zciss, Oberkochen, FRG). The apical surfacc of the saccular macula was viewed from above with differential-interference contrast optics and a $40 \times$ water-immersion lens with a numerical aperture of 0.75 .
With these optics one can resolve the components of hair bundles: the stereocilia and kinocilia. The chamber was perfused with $4 \mathrm{~mm} \mathrm{Ca}^{2+}$ perilymph (Table 1) at $5 \mu \mathrm{l} / \mathrm{sec}$.

In most experiments, membrane potential was recorded by penetrating the apical cell membrane with a glass micropipette. The pipettes were filled with $3 \mathrm{M} \mathrm{KCl}$ and had tip resistances of 150-300 M . Potential was recorded with a high-impedance preamplifier (model 701; W-P Instruments, Hamden, CT), then amplified and stored on tape. In several experiments, membrane current was recorded using a 2-electrode voltage clamp (Corey and Hudspeth, 1979a). Both electrodes were micropipettes filled with $3 \mathrm{M} \mathrm{KCl}$ and bevelled to resistances of $90 \mathrm{M} \Omega$. One microelectrode recorded membrane potential and the other passed current to clamp the membrane potential near the resting level, at -60 $\mathrm{mV}$.

The hair cells werc stimulated by deflecting the hair bundles with borosilicate glass probes pulled to $1-2 \mu \mathrm{m}$ tips. The probes were mounted on a piezoelectric bimorph device described in detail elsewhere (the "2-dimensional pi" device; Corey and Hudspeth, 1980). The probes were bent using a heated filament so that the final few millimeters were parallel to the plane of the macula. The motion of the probe in response to applied voltages was calibrated with an eyepiece micrometer. Displacements between -5 and $+5 \mu \mathrm{m}$ were a linear function of voltage. The probe was coupled to the hair bundle by inserting it between the kinocilium and the 5 adjacent stereocilia, below the kinociliary bulb (Fig. 3). Scanning and transmission electron micrographs indicate that the kinocilium is attached to the adjacent stereocilia only at, and just below, the kinociliary bulb (Fig. 2; Hillman, 1969). Insertion of the probe below the bulb provides good coupling and does not appear to disrupt the bundle (sec Fig. 13). The probe was driven with summed periodic and step stimuli. Periodic stimuli were triangle-wave or sinusoidal at $20-30 \mathrm{~Hz}$; steps were $50-200 \mathrm{msec}$ in duration and had a sigmoidal rise and fall of $10 \mathrm{msec}$ to avoid exciting the probe's resonance at approximately $300 \mathrm{~Hz}$.

Scanning electron microscopy. Preparations dissected as described above were tixed for $30 \mathrm{~min}$ at room temperature in $200 \mathrm{~mm}$ glutaraldehyde in a buffer solution containing $5 \mathrm{~mm} \mathrm{CaCl}$ and $45 \mathrm{~mm}$ HEPES at $\mathrm{pH}$ 7.2. After a wash in the same buffer solution, they were postfixed for $1 \mathrm{hr}$ at $4^{\circ} \mathrm{C}$ in $40 \mathrm{~mm} \mathrm{OsO}_{4}$ in the same buffer solution. They were then dehydrated in ethanol, critical-point dried from liquid $\mathrm{CO}_{2}$, and sputter-coated with gold-palladium prior to examination.

\section{Results}

\section{Saccular nerve activity}

Almost every neuron encountered in the saccular nerve increased its firing rate in response to vertical acceleration steps of one polarity only, either upward or downward. Steps of the opposite polarity had an inhibitory effect, seen as a decrease in firing rate in those neurons with background firing levels. Two ncurons out of the total of 106 rcsponded to both stimulus polarities with an increase in firing rate. In general, the neurons were sensitive to a larger range of acceleration amplitudes in the excitatory than in the inhibitory direction. The response pattern was determined by repeating a step many times and recording the timing of spike discharges relative to each step in a PST histogram. The neuron whose responses are shown in Figure 4 is representative. Figure $4 A$ shows a PST histogram of spike discharges evoked by an $8 \mathrm{msec}$ excitatory acceleration step. For excitatory steps of longer duration, the spike probability was greatest near the onset of the step, falling to background or near-background level within 10-20 msec (Fig. 4B). Therefore, bullfrog saccular neurons adapt to maintained excitatory acceleration. When a neuron is in an adapted state, it is capable of responding vigorously to a superimposed stimulus (Fig. $4 C$ ). The adaptation is thus not due to a desensitizing mechanism, such as the inactivation of ionic channels involved in the response.

For neurons with background discharge rates greater than 1 spike/sec, the reduction in discharge rate during maintained inhibitory stimuli also decayed during the step. For neurons 


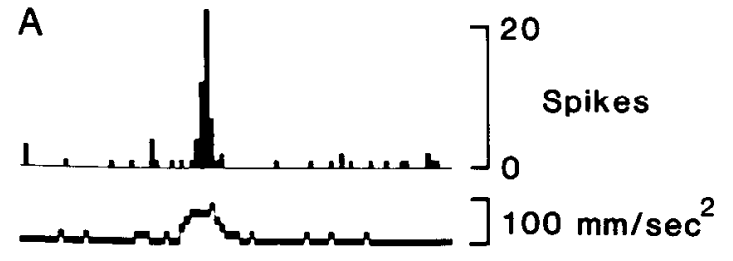

B



C


E



F

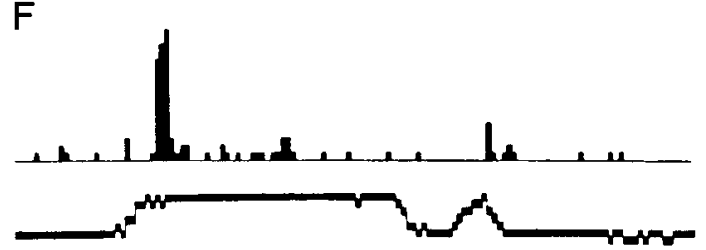

G

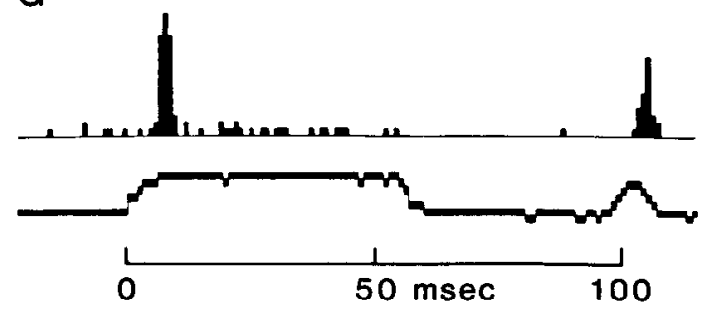

Figure 4. Peristimulus time (PST) histograms of the responses of a saccular neuron to vertical acceleration steps. The frog was prone during this experiment. The lower trace in each pair is the output of the accelerometer, averaged over 100 consecutive stimulus presentations. PST histograms (upper traces in each pair) were obtained by dividing the stimulus period into $1 \mathrm{msec}$ bins and counting the number of spikes with low background rates ( $<1$ spike/sec), inhibition of the background discharge was difficult to detect. However, inhibitory effects were demonstrated in all neurons tested by combining excitatory test steps with inhibitory adapting steps. For example, the response of the neuron in Figure $4 A$ to an excitatory step alone was greater than its response to an excitatory step superimposed on a step of opposite polarity (Fig. 4D); thus the latter had an inhibitory effect. This effect decayed with time after the onset of the inhibitory step, as shown by an increase in the response to the test step (Fig. 4, $D, E$ ).

A rebound in the response often occurred at the termination of an adapting step. In neurons with measurable background activity, the termination of an excitatory step evoked an undershoot relative to background (Fig. 4, B, C). Conversely, overshoots occurred at the termination of maintained inhibitory steps (Fig. 4, D, E). Adapting steps also affected responses to test steps delivered immediately afterward. The responses to test steps were depressed following an adapting step of the same polarity (Fig. $4 F$ ) and were enhanced following one of opposite polarity. These postadapting-step effects, like responses during the adapting steps, decayed with time following the step termination: the overshoot at the termination of the inhibitory steps in Figure 4, $D$ and $E$, decayed rapidly, and the sensitivity to the test step, depressed immediately after the excitatory adapting step (Fig. $4 F$ ), gradually recovered (Fig. $4 G$ ). The overshoot at the termination of an inhibitory stcp dccaycd at about the same rate as the response to the onset of an excitatory step (compare Fig. 4, $B$ and $D$ ). Often these responses decayed fully within 5-15 msec; sometimes there was a minor component to the response that decayed more slowly (Fig. $4, B, F, G$ ). The recovery of sensitivity to an excitatory test step following the onset of an inhibitory adapting step (Fig. 4, D, E) or the offset of an excitatory adapting step (Fig. $4, F, G$ ) took tens of milliseconds.

Possible sites of the adaptation observed in vivo. Adaptation of the discharge rate of saccular fibers could result from a variety of mechanisms (Fig. 1B). With the saccular nerve preparation, we were able to rule out important roles for either efferent or refractory mechanisms in the adaptation described above.

By recording from neurons before and after transection of the eighth nerve near the medulla, we found that efferents of central origin do not play a role in the adaptation described above. In each of 2 experiments, responses were recorded from 2 neurons

that occurred in each bin during 100 stimulus periods. The stimuli are combinations of relatively long-duration upward and downward adapting steps and short upward test steps. Whether the frog was prone or supine, upward accelerations are expressed as positive. In this figure, the baseline is the steady acceleration due to gravity. Discharge rate in this neuron increased during upward accelerations only; other neurons responded to downward accelerations only. $A$, The upward test step alone. $B$, The upward adapting step alone. The probability of firing was greatest 7-9 msec after the onset of the step, falling to background level within $20 \mathrm{msec}$. The discharge rate fell to zero immediately after the termination of the step, recovering to background level in $30 \mathrm{msec}$. $C$, The test step superimposed $11 \mathrm{msec}$ after the onset of the adapting step, when the discharge rate to the adapting step alone had decayed below $10 \%$ of its peak value. $D, E$, Test step superimposed on a downward adapting step that inhibited the low background level of firing in this neuron. The test step began $8(D)$ or $40(E)$ msec after the onset of the downward step. $F, G$, Postadapting step effects on the responses to test steps. The test step was presented $11(F)$ or $42(G)$ msec after the termination of the excitatory adapting step. 


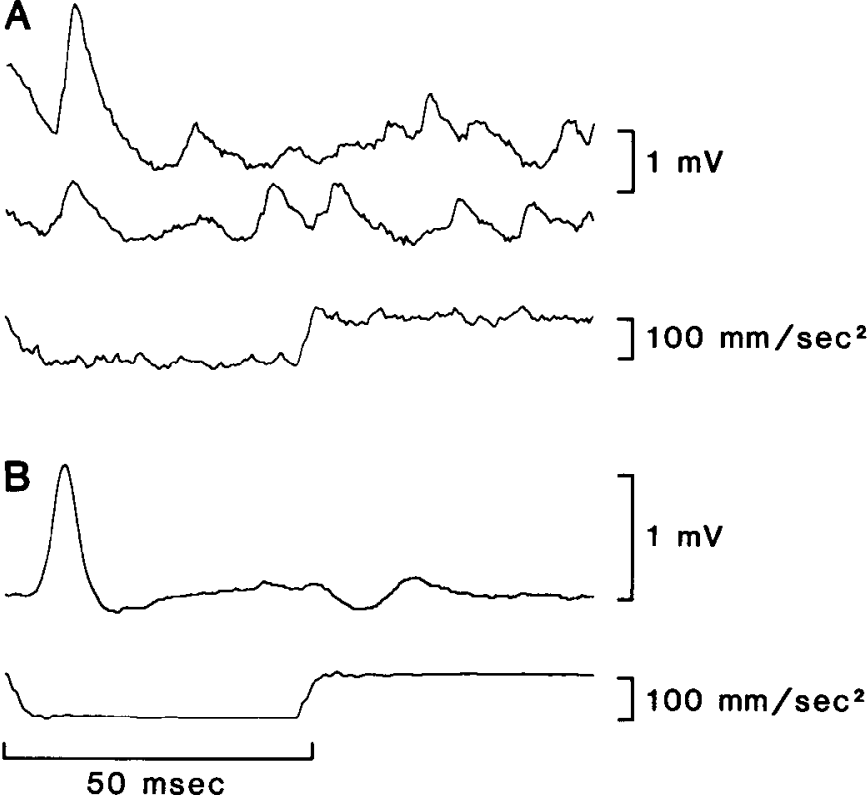

Figure 5. Postsynaptic potentials in a saccular nerve fiber in response to steps of vertical linear acceleration. The frog was supine for this experiment. The fiber was penetrated near its termination in the saccular macula and was treated with tetrodotoxin, greatly reducing spiking. The acceleration stimulus was a $10 \mathrm{~Hz}$ square-wave acceleration, symmetrical about the rest position of the platform, with a peak-to-peak magnitude of $0.12 \mathrm{~m} / \mathrm{sec}^{2}$. A, The lowermost trace shows a single stimulus sweep; slightly less than one full period is shown. The upper two traces are consecutive intracellular voltage records and illustrate the variability in timing of individual postsynaptic events relative to the stimulus. $B$, Averages of simultaneous voltage and stimulus records from the same neuron as in $A$. Approximately $20 \mathrm{sec}$ of data, corresponding to 183 intervals of $95 \mathrm{msec}$, were averaged. Several spikes occurred in this period and were excluded from the average.

after nerve transection; the data in Figure 4 are from one of these neurons. The results from all 4 neurons were at least qualitatively similar to those obtained from other cells before nerve transection, showing both adaptation and the associated changes in sensitivity to test steps applied during or after adapting steps.

Because the neurons can respond to new stimuli when adapted to a maintained stimulus (Fig. 4C), a desensitizing mechanism, such as spike refractoriness, cannot account entirely for the observed adaptation. However, refractoriness could contribute to decays in discharge rate. To address this possibility, we recorded intracellularly near the fibers' terminals in the macula and applied tetrodotoxin to the nerve, greatly reducing or abolishing spike activity for minutes. During this interval, we observed frequent EPSPs similar in appearance to those in other eighthnerve preparations (Rossi et al., 1977; Furukawa and Matsuura, 1978; Schessel and Highstein, 1981), ranging in amplitude from one-tenth to several millivolts (Fig. $5 A$ ). Averages of these records revealed a clear relation between the probability of postsynaptic potentials and the steps (Fig. $5 B$ ). The averaged voltage record shares many of the features of a PST histogram for a similar stimulus. A prominent depolarizing potential occurs after the onset of excitatory steps, then decays to the prestep level in 5-10 msec from the peak of the potential. This depolarization coincides with the peak in spike count in PST histograms. A small hyperpolarization is often seen at the termination of the excitatory step (Fig. $5 B$ ). This hyperpolarizing potential decays



Figure 6. In vivo microphonic potential in response to vertical linear accelerations. In $A$, a $26 \mathrm{~Hz}$ sine wave, and in $B$, an $8.1 \mathrm{~Hz}$ squarewave were applied to the shaker. The resulting acceleration stimuli were symmetric about the rest position of the shaker and had peak-to-peak magnitudes of 0.2 and $0.18 \mathrm{~m} / \mathrm{sec}^{2}$, respectively. Both voltage and stimulus records have been averaged. To facilitate comparison with intracellular records, we show negative-going microphonic potentials, which correspond to depolarization of the hair cells, as upward deflections. $A$ and $B$ are from different animals. Both were supine during the experiments.

in 10-20 msec and has a counterpart in the PST histograms of neurons with background discharge, which show a reduced spike probability at the offset of excitatory steps.

Since the averaged postsynaptic potentials adapted at about the same rate as spike probability, refractory processes such as sodium-channel inactivation do not contribute significantly to the adaptation. In the goldfish sacculus, adaptation of the afferents' discharge during tone bursts also reflects adaptive changes in EPSPs (Kuno, 1983). In both the goldfish sacculus and the mammalian cochlea, the afferent synapse has been implicated in the adaptation of afferent fiber responses to acoustic tone stimuli (Furukawa and Matsuura, 1978; Furukawa et al., 1982; Smith et al., 1983). To determine whether the afferent synapse contributes to the adaptation described here, we recorded the extracellular hair cell response for comparison with the saccular neurons' postsynaptic potentials.

\section{In vivo microphonic potential}

The extracellular response from the saccular hair cells, the microphonic potential, was recorded by advancing a microelectrode into the otoconial mass, which is within the endolymphatic compartment of the sacculus. When acceleration stimuli were applied, stimulus-locked potentials, $0.1-2 \mathrm{mV}$ in amplitude, were recorded. We assume for 2 reasons that these potentials were due primarily to receptor currents across the hair cell membranes. First, the potentials were not mechanical artifacts, as they disappeared after the animal died. Second, during sinusoidal accelerations, the potentials took the form of oscillations with a dominant component at twice the stimulus frequency (Fig. $6 A$ ). This " $2 \mathrm{f}$ " response to an alternating stimulus is characteristic of hair cell organs with hair cells of opposing orientations, and is a consequence of the rectified stimulus- 
response relations typical of hair cells (Flock, 1965; Corey and Hudspeth, 1983a).

The averaged responses to sinusoidal and square-wave stimuli in Figure 6 are typical; approximately equal potentials were evoked by each half-cycle. During square-wave stimulation, the potential peaked 3-5 msec after the completion of each transition, then decayed to baseline within $10 \mathrm{msec}$. This complete adaptation of the microphonic potential indicates that essentially all of the hair cells adapted. The rate of adaptation of the microphonic potential was similar to that of the neural responses. These rates could be compared directly in 2 preparations in which both postsynaptic and microphonic potentials were recorded. Taking the time to decay to $e^{-1}$ times the peak value as an estimate of adaptation rate, the ratio of decay times for the averaged postsynaptic potentials and microphonic potentials varied from 0.7 to 1.4 . Therefore, the afferent synapse does not play a dominant role in the adaptation described here.

The heterogeneity in hair cell orientation in the intact sacculus complicates interpretation of the microphonic potential, since the depolarizing response of one group of cells is superimposed on the hyperpolarizing response of the other. Analysis of the sources of adaptation in the microphonic potential in vivo is also difficult because the micromechanical input to the hair cells cannot be directly observed. Our approach to this problem was to study the hair cell response in excised, in vitro preparations, where the stimulus can be controlled.

\section{In vitro microphonic current}

A group of several hundred hair cells of similar orientation was stimulated en masse by moving the overlying otolithic membrane, to which the hair bundles were attached. The total current passing across the sensory epithelium in response to the displacement of the otolithic membrane was measured. We have presented evidence elsewhere (Corey and Hudspeth, 1983a) that the microphonic current measured in this way is the sum of receptor currents passing through transduction channels in the stereocilia (Hudspeth, 1982) and of other ionic currents passing through channels in the hair cell membranes. The latter are voltage- and ion-dependent channels that are activated secondarily to the voltage change produced by the receptor current (Lewis and Hudspeth, 1983). It is possible to block most of this indirectly activated microphonic current by bathing the basolateral surfaces of the cells in a high- $\mathrm{K}^{+}$artificial perilymph (Table 1); this partially depolarizes the cells, lowering their input resistances, and thus substantially reduces the voltage change produced by a given receptor current (Corey and Hudspeth, 1983a). This technique was employed in most of the experiments presented here, so that the measured microphonic current was dominated by the receptor currents of stimulated cells.

The stimuli were maintained displacements applied to the otolithic membrane with a stimulus probe. Such stimuli are analogous to the maintained accelerations applied in the in vivo experiments: as described in the introduction, linear acceleration of the animal stimulates the saccular hair cells by displacing the overlying otoconial mass and otolithic membrane (Figs. 1, 2). To ensure that constant displacements of the stimulus probe produced constant displacements of the otolithic membrane, we measured the position of the otolithic membrane with an optical monitor focused on a clump of otoconia embedded in the otolithic membrane.

When a maintained displacement was applied to the otolithic membrane in vitro, the microphonic current rose to a peak, then



Figure 7. In vitro microphonic current in response to a maintained displacement of the otolithic membrane. This preparation was perfused apically with normal endolymph, and basally with high- $\mathrm{K}^{+}$perilymph. The elevated $\mathrm{K}^{+}$in the lower bath depolarizes the hair cells to approximately $-50 \mathrm{mV}$. Under these conditions, the microphonic current primarily represents the receptor current of stimulated cells. A, Microphonic current. Current passing from the upper to the lower baths, corresponding to inward (depolarizing) current across the apical surfaces of the hair cells, is shown in the upward direction. $B$, Optical milunitor of the position of the otolithic membrane. The trace shows no slippage in the otolithic membrane's position. $C$, Step stimulus applied to the piezoelectric device to which the stimulus probe was attached. Stimuli that deflect the underlying hair bundles in the direction of their kinocilia are shown as upward and referred to as positive.

declined (Fig. 7A). This was not due to slippage between the stimulus probe and otolithic membrane, as is indicated by the optical measurement of the otolithic membrane position (Fig. $7 B$ ). The hair cell response to a maintained displacement of the otolithic membrane, therefore, adapts. At the termination of the step, the response showed an undershoot below its resting level, then recovered over the next few hundred milliseconds.

In an earlier paper (Corey and Hudspeth, 1983a), we argued that when the hair cells are depolarized by the high- $\mathrm{K}^{+}$perilymph, the decline in microphonic current during a maintained step is due to a shift in the preparation's displacement-response function along the stimulus axis. The displacement-response curve of the microphonic current preparation reflects the summed displacement-response curves of the individual hair cells contributing to the microphonic current. We have demonstrated the displacement shift in the microphonic-current preparation more completely, and have measured its time course, by determining the displacement-response curve before and at various times during a maintained adapting step (Fig. 8). For this experiment, each stimulus was the superposition of a $100 \mathrm{msec}$, $250 \mathrm{~nm}$ adapting stcp and a $5 \mathrm{mscc}$ test step. On each successive stimulus presentation, the test step was assigned one of 16 displacements and one of 13 times relative to the adapting step (Fig. $8 B$ ). In this way, 13 displacement-response curves were generated, each at a given time before, during, or after the adapting step (Fig. 8C). Comparison of curves generated at different times shows that during an adapting step the curve shifted along the displacement axis in the direction of the adapting displacement, then shifted back at the termination of the step. In effect, this displacement shift resulted in a reduction of the stimulus to the transduction mechanism, and thus in a decay of the microphonic current evoked by the adapting step. In general, most of the decay of the microphonic current was due to the displacement shift. However, during a positive adapting step, 
A
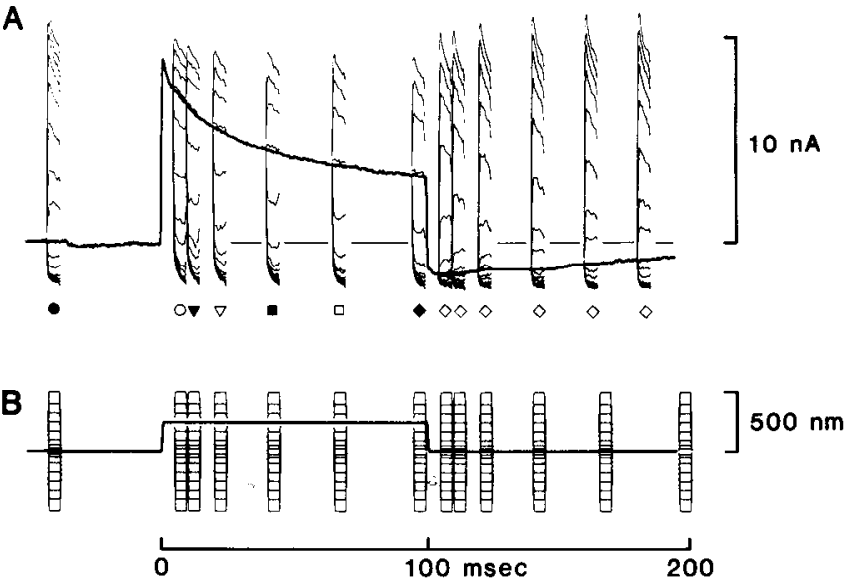

C

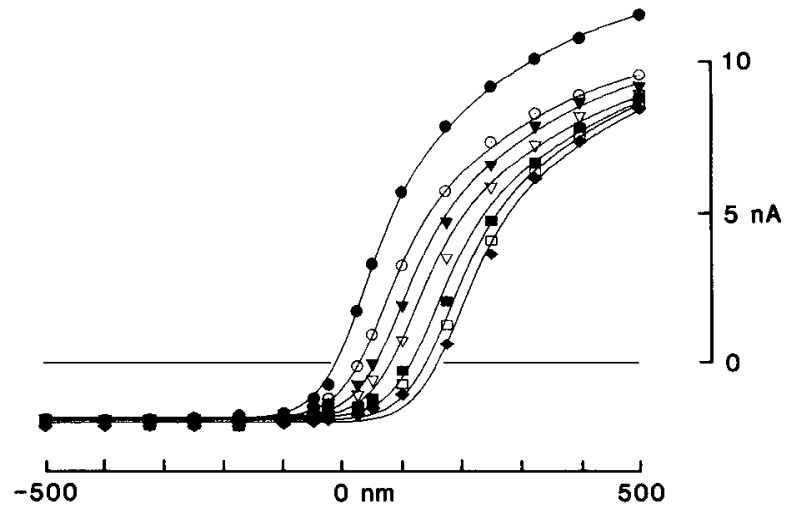

D

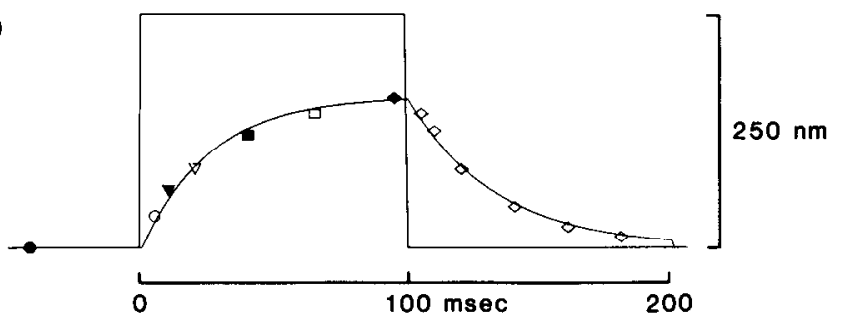

E

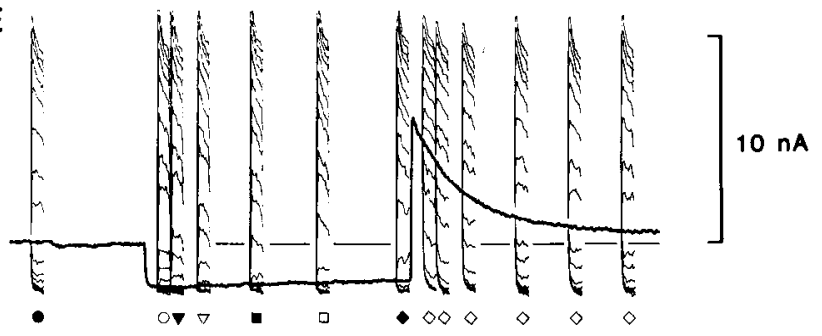

F

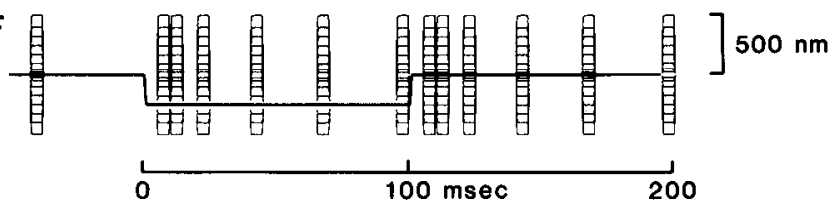

G

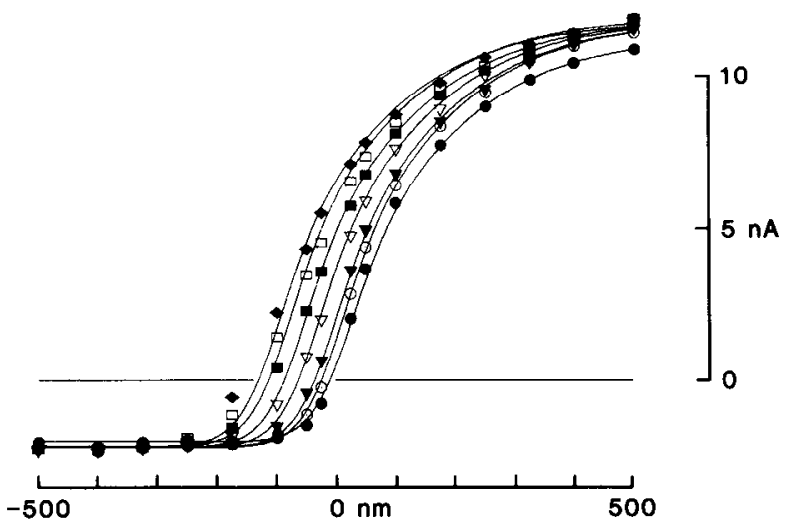

$H^{-}$

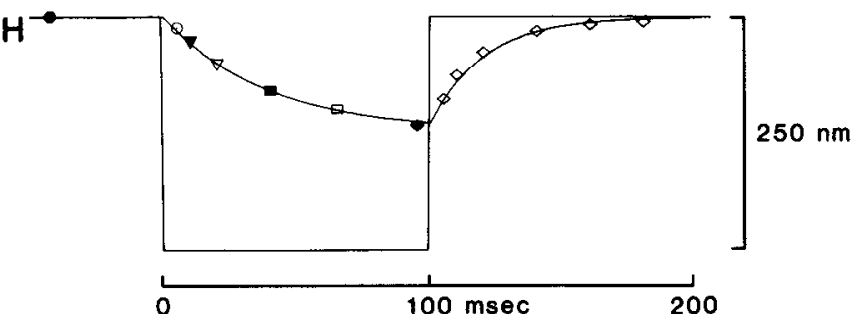

Figure 8. Displacement shift in the displacement-response curve during adapting steps $\pm 250 \mathrm{~nm}$ in amplitude. $A$, The microphonic current in response to a positive adapting step and superimposed test steps. Symbols beneath the sets of responses are used to plot the corresponding data in panels $B-H$. $B$, Each stimulus consisted of the adapting step and one test step; the test step's amplitude and timing were varied over 16 levels and 13 delays. The stimuli were presented at a rate of $1 / \mathrm{sec}$. $C$. The set of responses to test steps presented at a given time was used to construct a displacement-response curve for that time. A smooth curve was fitted to the displacement-response data measured before the adapting step, then was shifted along the displacement axis to fit subsequent data. When necessary, the curve was scaled vertically to adjust for changes in the driving force on the receptor current. Data obtained during the recovery period at the step's termination are not shown. $D$, Time course of the displacement shift. The shift of the smooth curve required to fit the displacement-response data was plotted against time during the adapting step; symbols match those for the displacement-response data. The amplitude and time course of the adaptive step are also shown. The time course of the shift during the adapting step was fitted with an exponential curve with a time constant of $26 \mathrm{msec}$ and an amplitude of $160 \mathrm{~nm}$; the time constant of recovery from the adapting step was $32 \mathrm{msec}$. $E-H$, The same experiment for a negative adapting step, also $250 \mathrm{~nm}$. The curve fitted to the adaptive shift had a time constant of $38 \mathrm{msec}$ and an amplitude of $120 \mathrm{~nm}$, while the recovery time constant is 20 msec. The preparation was perfused apically with $1 \mathrm{mM} \mathrm{Ca}^{2+}$ endolymph and basally with high-K $\mathrm{K}^{+}$perilymph.

some of the decay resulted from a decrease in the driving force for the receptor current as the hair cells depolarized, as shown by the decrease in the maximum amplitude of the response (Corey and Hudspeth, 1983a). When this occurred, the displacement-response curve was compressed along the response axis relative to the resting curve (Fig. $8 \mathrm{C}$ ). Apart from this, the shape of the displacement-response curve was largely unaffected by the adapting step. A negative adapting shift in response to a negative displacement step was determined in the same way (Fig. 8, E-G). In this case, the maximum amplitude of the response increased slightly, because of hyperpolarization of the hair cells during a negative step. Again, the shape of the curve was largely unaffected, so that the shift could be independently measured.

The displacement shifts observed in vitro can account qualitatively for the effects of adapting acceleration steps upon saccular neurons' responses to test steps in vivo (Fig. 4). Such shifts in the hair cells' displacement-response curves would lead to decay of the saccular neurons' response to a maintained acceleration (Fig. $4 B$ ) without loss of sensitivity to superimposed test 
steps (Fig. 4C). A large adapting acceleration step, either positive or negative, would initially drive hair cells into the insensitive (low-slope) portions of the nonadapted displacement-response curves. The displacement-shift process would, however, lead to a gradual recovery of sensitivity. This effect on hair cell responses could explain the gradual increase in saccular neurons' responses to excitatory test steps during an inhibitory adapting step (Fig. 4, D, E). Rebounds in the microphonic current occurred at the termination of adapting steps (Figs. $8 E, 12$ ) because the shift process moved the sensitive region of the hair cells' displacement-response curves in the direction of the adapting displacement. Such rebounds in the hair cells' responses would result in rebounds in saccular neurons' activity at the termination of acceleration steps (Fig. $4, D, E$ ). Finally, the gradual return of the hair cells' displacement-response curves to their resting positions following an adapting displacement would cause a gradual recovery of saccular fibers' test step responses following an adapting step, as is observed (Fig. $4, F, G$ ).

Despite this qualitative agreement between the in vitro and in vivo effects, the time courses and extents of the 2 sets of observations differ quantitatively. We consider possible sources of these differences in the Discussion.

Time course of the displacement shift. The displacement shifts required to align the displacement-response curves were plotted against time during the adapting step (Fig. 8, $D, H$ ). Three features of the time course of the displacement shift are noteworthy. First, the time courses of the displacement shift and of the decay of the microphonic current are similar, but not identical, because the relation between displacement and current is nonlinear. Second, the shift and the decay are not complete after $100 \mathrm{msec}$, the standard duration of the adapting steps used in this preparation. For most preparations, with approximately normal $\mathrm{Ca}^{2+}$ concentrations on the apical and basolateral cell surfaces, the displacement shift reached $60-90 \%$ of the amplitude of the adapting displacement within $100 \mathrm{msec}$. Third, the time course is roughly fitted by a single exponential curve with a time constant on the order of $30 \mathrm{msec}$. A better fit is obtained with a sum of 2 exponential functions of roughly equal amplitude and with time constants of 10-20 and 100-200 msec (Corey and Hudspeth, 1983a). This may reflect either a complex time course of adaptation in individual hair cells or the summation of time courses that are simple but different among cells.

Amplitude dependence. In a given preparation, the shifts during the adapting steps of different amplitude followed roughly similar time courses (Fig. 9). However, the amplitude of the shift at any given time during the adapting step was not proportional to the step amplitude: expressed as a percentage of the adapting displacement, the shift was smaller for larger steps. For example, at $100 \mathrm{msec}$ in the experiment in Figure 9, the shift was 86,76 , and $66 \%$ of the +210 , +400 , and $+770 \mathrm{~nm}$ steps, respectively. The displacement-shift process is therefore a nonlinear function of displacement.

Asymmetry in the rate of the displacement shift. The rates of shift during positive and negative stops of equal amplitude differ. In the experiment shown in Figure 8, for instance, the initial rate of the shift (measured as the initial slope of the fitted exponential curve) was $6.2 \mu \mathrm{m} / \mathrm{sec}$ for the positive step (Fig. 8D) but only $3.2 \mu \mathrm{m} / \mathrm{sec}$ for the negative step (Fig. $8 H$ ). If the shift is slower for negative stimuli, then an oscillatory stimulus with equal negative and positive components should result in a net positive shift. This was tested in the experiment in Figure 10. The displacement-response curve was determined using step

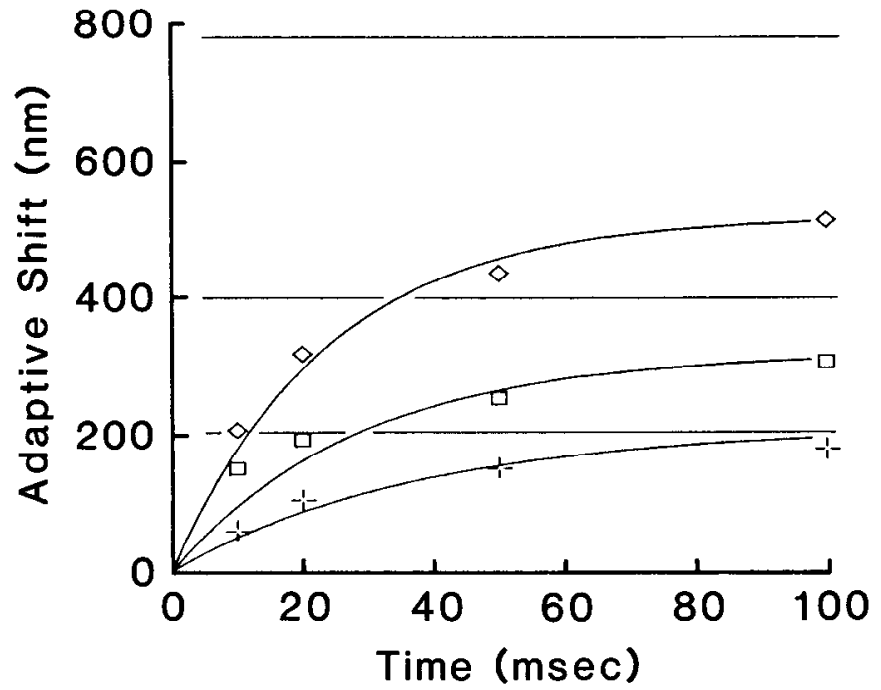

Figure 9. Amplitude dependence of the time course of the displacement shift in the microphonic current preparation. Adapting steps (100 $\mathrm{msec}$ ) of 3 different amplitudes, indicated by the horizontal lines, were used. The displacement shift, measured as described for Figure 8 , is plotted against time after the onset of steps of +210 (crosses), +400 (squares), and +770 (diamonds) $\mathrm{nm}$. The preparation was perfused apically with normal endolymph and basally with normal perilymph.

displacements before and immediately after a $100 \mathrm{msec}$ sinusoidal burst of $900 \mathrm{~Hz}$ and $1 \mu \mathrm{m}$ peak-to-peak displacement. During this symmetrical stimulus, the displacement-response curve shifted $+100 \mathrm{~nm}$. Such a shift is inhibitory in that it leads to reduction in the inward receptor current.

Temperature dependence of the rate of the displacement shift. We characterized the temperature dependence of the process by measuring the initial rate of the shift in response to a $+400 \mathrm{~nm}$ adapting step at $10^{\circ}$ and $20^{\circ} \mathrm{C}$ (data not shown). The initial rate was determined as the initial slope of an exponential curve fitted as in Figure $8, D, H$. In 2 experiments, the initial rate at $20^{\circ} \mathrm{C}$ was twice that at $10^{\circ} \mathrm{C}$, indicating a thermal $Q_{10}$ for the process of about 2 . This value is consistent with an active mechanism.

Calcium dependence. Calcium ions in the solution bathing the apical hair cell surface seem to play an important role in mechanoelectrical transduction. Reduction of the $\mathrm{Ca}^{2+}$ concentration below $10 \mu \mathrm{M}$ has been reported to block mechanoelectrical transduction by hair cells (Sand, 1975; Hudspeth and Corey, 1977; Ohmori, 1985). In other studies with the bullfrog's sacculus, alteration of the apical $\mathrm{Ca}^{2+}$ concentration within the physiological range reversibly affected both the kinetics of mechanoelectrical transduction and the shape of the displaccmentresponse curve (Corey and Hudspeth, 1983b).

Calcium at the apical hair cell surface modulates the adaptation mechanism as well. In the experiment shown in Figure 11 , the shift of the displacement-response curve was measured as above, and the $\mathrm{Ca}^{2+}$ concentration of the artificial endolymph was changed (Table 1). Increasing the extracellular $\mathrm{Ca}^{2+}$ from 0.1 to $1 \mathrm{~mm}$ increased both the initial rate and final extent of the adaptive shift. A further increase from 1 to $10 \mathrm{mM} \mathrm{Ca}^{2+}$ produced little if any increase, suggesting that the $\mathrm{Ca}^{2+}$ effect is saturable. Addition of $2 \mathrm{~mm} \mathrm{Sr}{ }^{2+}$ to endolymph containing 1 $\mathrm{mM} \mathrm{Ca}^{2+}$ slowed the rate of shift (data not shown), suggesting that $\mathrm{Sr}^{2+}$ may compete with $\mathrm{Ca}^{2+}$ for a site regulating adaptation.

Lack of simple dependence of the displacement shift on ion 
A


Figure 10. Displacement shift during a symmetric stimulus. The displacement-response curve was measured with test steps before and immediately after a $100 \mathrm{msec}$ sinusoidal burst at $900 \mathrm{~Hz}$. The preparation was perfused apically with normal endolymph and basally with normal perilymph.

entry. Two observations suggested a possible mechanism for the displacement shift during adaptation. First, the resting displacement-response curve shifts positively along the displacement axis when $\mathrm{Ca}^{3+}$ is increascd over the range $0.05-10 \mathrm{mM} \mathrm{Ca}^{2+}$ (Corey and Hudspeth, 1983b). Second, the transduction channel is permeable to $\mathrm{Ca}^{2+}$ (Corey and Hudspeth, 1979a; Ohmori, 1985). These observations suggested that the $\mathrm{Ca}^{2+}$ influx through transduction channels during a positive step might increase intracellular $\mathrm{Ca}^{2+}$ and act at an intracellular site to shift the displacement-response curve positively. A negative step would decrease $\mathrm{Ca}^{2+}$ influx, lowering intracellular $\mathrm{Ca}^{2 \mid}$ and causing a negative displacement shift. The experiment in Figure 12 tested this idea.

Figure 12 shows the microphonic current in response to brief

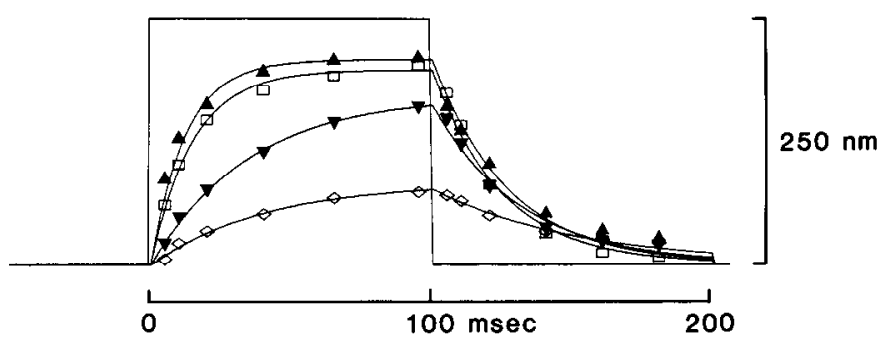

Figure 11. $\mathrm{Ca}^{2+}$ dependence of the displacement shift in the microphonic current preparation. The time course of this adaptive shift during a $+250 \mathrm{~nm}, 100 \mathrm{msec}$ adapting step was measured as in Figure 8, with 4 different $\mathrm{Ca}^{2+}$ concentrations in the artificial endolymph bathing the apical surfaces of hair cells. The $\mathrm{Ca}^{2+}$ concentrations, and the exponential fits to the data, were as follows $\left(\mathrm{Ca}^{2+}\right.$ concentration, adapting time constant, recovery time constant, and amplitude of the exponential curves): diamonds, $0.1 \mathrm{~mm}, 39 \mathrm{msec}, 56 \mathrm{msec}, 80 \mathrm{~nm}$; inverted triangles, $0.25 \mathrm{~mm}, 34 \mathrm{msec}, 31 \mathrm{msec}, 160 \mathrm{~nm}$; squares, $1 \mathrm{~mm}, 15 \mathrm{msec}, 22 \mathrm{msec}$, $200 \mathrm{~nm}$; triangles, $10 \mathrm{~mm}, 12 \mathrm{msec}, 26 \mathrm{msec}, 210 \mathrm{~nm}$. The preparation was perfused basally with high- $\mathrm{K}^{+}$perilymph. Other experiments produced qualitatively similar results, particularly the apparent saturation of the $\mathrm{Ca}^{2+}$ dependence above $1 \mathrm{~mm}$.
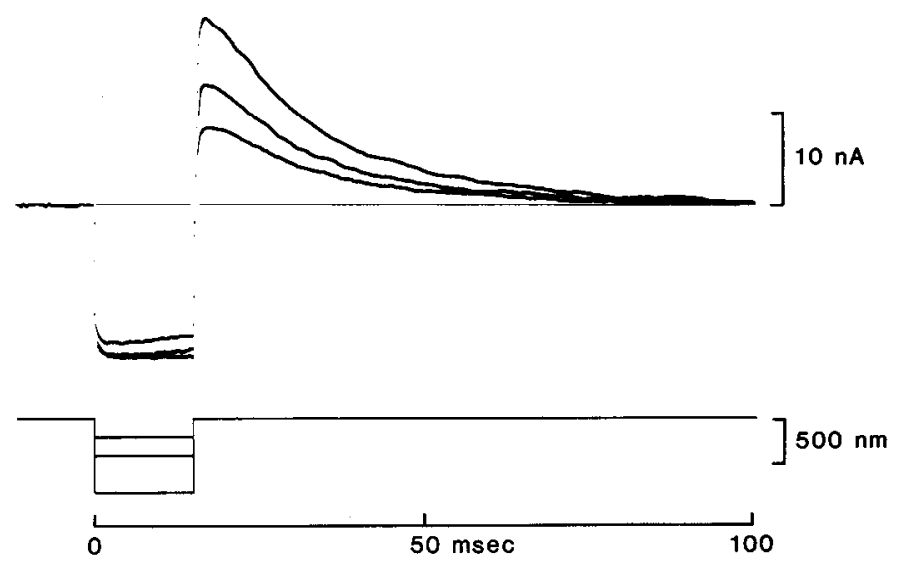

Figure 12. The displacement shift is sensitive to displacements that saturate mechanoelectrical transduction. In this figure, the three $20 \mathrm{msec}$ steps have amplitudes of $-200,-400$, and $-800 \mathrm{~nm}$. The latter 2 steps were both saturatingly large in terms of the displacement-response relation, and little response decay occurred during the steps. The rebound at the termination of the step was largest for the $-800 \mathrm{~nm}$ step, however, indicating that the displacement-response curve shifted farthest during the largest step. The preparation was perfused apically with $1 \mathrm{mM} \mathrm{Ca}^{2+}$ endolymph and basally with normal perilymph.

negative steps of different amplitudes: $-200,-400$, and -800 $\mathrm{nm}$. The 2 larger steps saturated the response, evoking maximal reductions in the resting current. Note that although the currents during these steps were similar, the rebound currents at the terminations of the steps varied with step amplitude. The amplitude of the rebound indicates the amplitude of the displacement shift that occurred during the step; thus, the displacement shift during the step varied with step amplitude, even though the amplitude of the receptor current was constant. This argues against a simple model in which the displacement shift is directly related to the amount of ion entry during a step. In addition, by demonstrating that the displacement-shift process is sensitive to displacements that saturate the mechanoelectrical transduction process, this experiment suggests that the shift process occurs at a stage preceding the gating of transduction channels.

\section{In vitro intracellular recordings from hair cells}

The microphonic current data do not indicate whether the shift process occurs in the hair cells or is a relaxation in the connections between the hair bundles and the otolithic membrane. To further localize the process, we removed the otolithic membrane and recorded from individual hair cells. Each cell was stimulated by deflecting its hair bundle with a glass microprobe inserted between the kinocilium and the adjacent stereocilia (Fig. 3). Stimuli are expressed as the displacement of the hair bundle at the height of probe contact, about $6 \mu \mathrm{m}$ above the base of the hair bundle.

Probe coupling. Coupling between a probe and hair bundle was assessed by watching through the light microscope while moving the probe slowly back and forth 1-2 $\mu \mathrm{m}$ along the bundle's axis of bilateral symmetry. Coupling was considered acceptable only if the hair bundle moved as a unit with the probe and with no visible lag. To check our ability to assess the position of the hair bundle with the light microscope, we performed the following experiments.

In 17 preparations, a stimulus probe was inserted between the kinocilium and the adjacent row of stereocilia in a hair bundle and was then statically displaced. The displacements, 

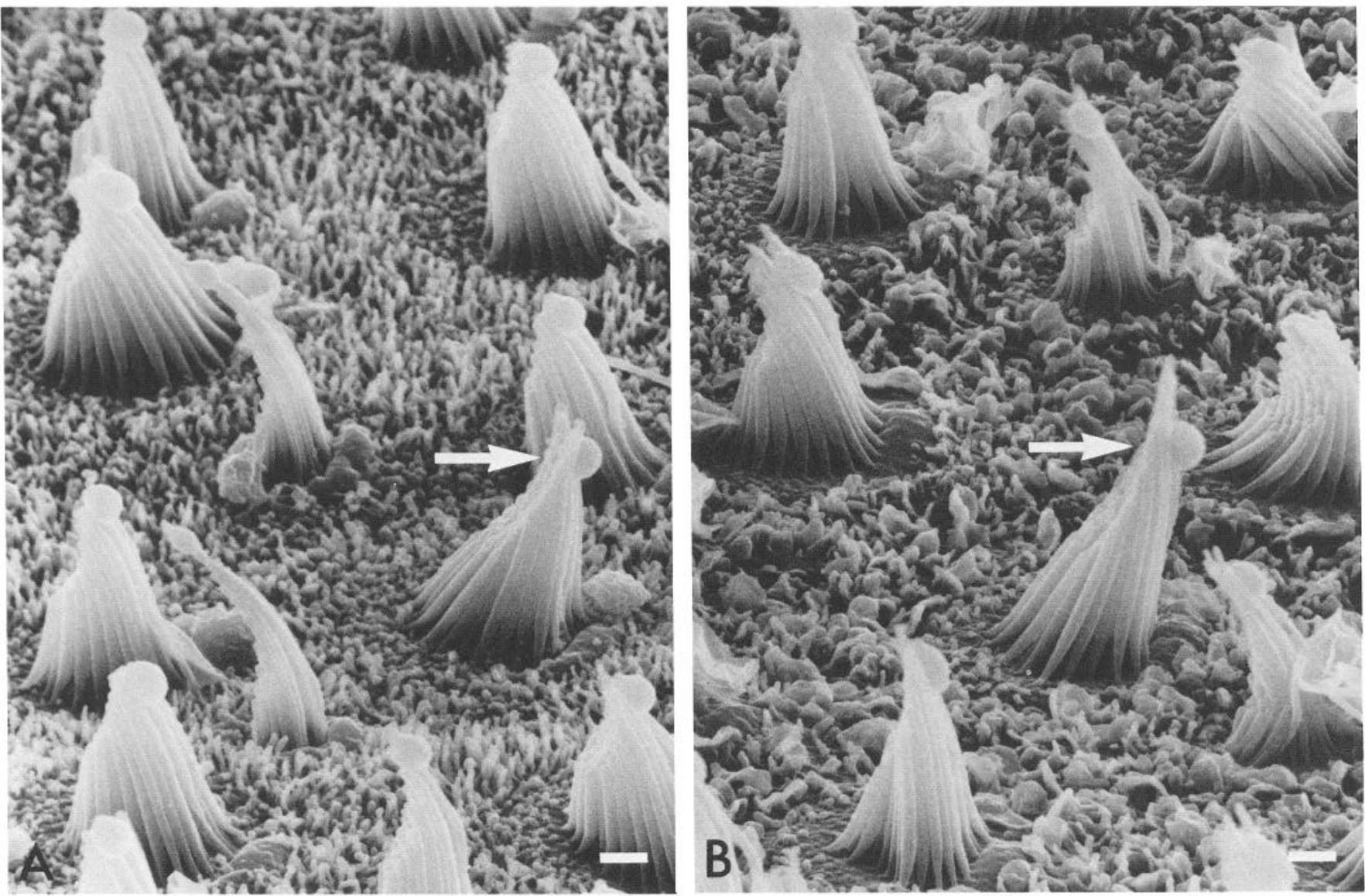

Figure 13. Scanning electron micrographs of statically deflected hair bundles. $A$ and $B$ are from different animals. In each instance, while a single bundle was statically deflected with a stimulus probe in the direction shown by the arrow, fixative was perfused through the bath. Note that, by comparison with the positions of the neighboring, nonstimulated bundles, each of the 2 stimulated bundles is deflected in the positive direction. The amplitude of deflection, measured near the tips of the hair bundles and corrected for viewing angle and tissue shrinkage, is slightly more than $2 \mu \mathrm{m}$ in each case. Scale bars, $1 \mu \mathrm{m}$.

which were confirmed by measurement with an eyepiece micrometer, ranged from -4 to $+5 \mu$ m relative to rest position; the smallest displacement was $+500 \mathrm{~nm}$. With the probe held in position, a glutaraldehyde fixative solution was then washed through the bath. The probe was removed after several minutes and the location of the deflected hair bundle was marked by destroying some neighboring hair bundles and diagramming the pattern of destruction. These maps allowed us to identify the hair bundle of interest in the scanning electron microscope (Hudspeth and Jacobs, 1979). In every case, the stimulated bundle was at an angle to other hair bundles (Fig. 13). By comparing the angle of the deflected bundle with the average for the control bundles in micrographs such as those in Figure 13, we estimated the displacement of the tip of the deflected bundle. The ratios of the displacement, as measured with the eyepiece micrometer, and the displacement, measured from the scanning micrographs, had a mean value of $1.0 \pm 0.1$ (SEM). In addition, the deflected bundles did not appear damaged and each had moved as a unit when the probe was displaced. These observations showed that a maintained displacement of the probe resulted in a maintained displacement of the hair bundle.

In vitro receptor potential. When the hair bundle was deflected towards the kinocilium, the cell rapidly depolarized. If the hair bundle was held in the new position, this receptor potential usually adapted. In Figure $14 A$, for example, the response to a step displacement began to decay immediately after an initial peak, falling within $100 \mathrm{msec}$ to a plateau value that was approximately $20 \%$ of the peak voltage. Fifty-seven of the 69 cells studied adapted to a maintained stimulus, either partially or completely.

Triangle-wave or sinusoidal displacements of the hair bundle were used to test the sensitivity of the cells at various times relative to the adapting step. In this preparation, as in the others, adaptation was not due to desensitization or inactivation, as the responses to saturatingly large test stimuli did not diminish with time during the adapting step (Fig. 14B). The test stimuli, like the test steps in the microphonic current preparation, were used to measure the displacement-response curves of single cells at different times relative to the adapting step. These curves were generated by plotting voltages against the corresponding displacement values for portions of the stimulus cycle (Fig. 14C). Although these are not instantaneous functions, the intervals are short enough to provide information about changes during the adapting step. After the step onset, the displacement-response curve, like that of the microphonic current, shifted with time along the displacement axis in the direction of the step. Displacement shifts during adapting steps were consistently observed in cells that adapted. Shifts along the voltage axis and expansion or compression along either axis (shape changes) were sometimes seen but did not appear to be systematic. 

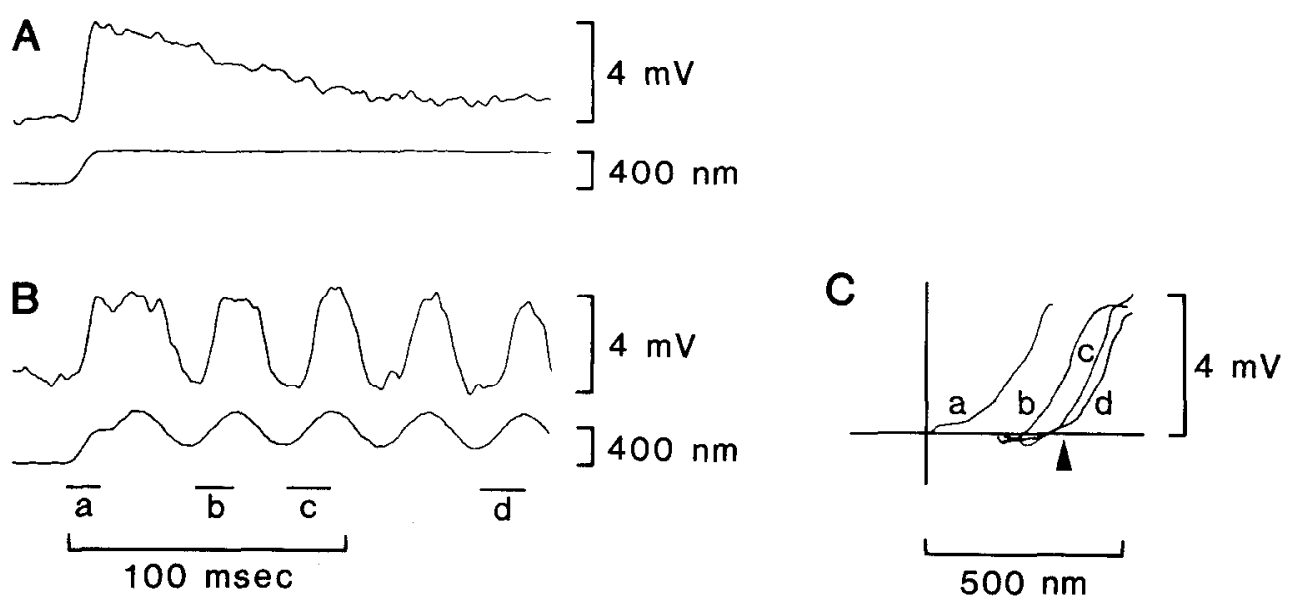

Figure 14. $\Lambda$ daptation of the intracellular receptor potential to a step displacement of the hair bundle. In this and subsequent figures, the preparation was superfused with $4 \mathrm{mM} \mathrm{Ca}^{2+}$ perilymph, and the response and stimulus records were averaged (5-20 trials) and smoothed. $A$, Response to a $+350 \mathrm{~nm}$ adapting step. $B$, Response to a $+350 \mathrm{~nm}$ adapting step with a superimposed $30 \mathrm{~Hz}$ sine wave. $C$, Displacement-response curves generated from the data in $B$. Each curve was obtained during a time window indicated below the stimulus record in $B$. The origin indicates the resting hair bundle position and membrane potential, and the arrowhead indicates the step displacement. Curve $a$ depicts the nonadapted displacement response relation at the onset of the step. Curves $b-d$ correspond to successively later times during the step and show that the displacement-response relation shifted along the displacement axis in the direction of the step.

Figure 15 compares the effects of positive and negative steps on the sensitivity of a cell to a $20 \mathrm{~Hz}$ triangle-wave stimulus. The onset of the step evoked a large depolarization and a transient reduction in the oscillating response to the triangle-wave. The triangle-wave response returned to its prestep amplitude within $150 \mathrm{msec}$. The termination of the positive step also caused an initial reduction of the trianglc-wave response, which recovered much more slowly than in Fig. $15 \mathrm{~A}$, reaching full amplitude only after $600 \mathrm{msec}$ (Fig. 15B). The recovery of test responses following a step to a new hair bundle position was generally slower for negative than for positive steps.

The displacement shift in single cells increased with step am-

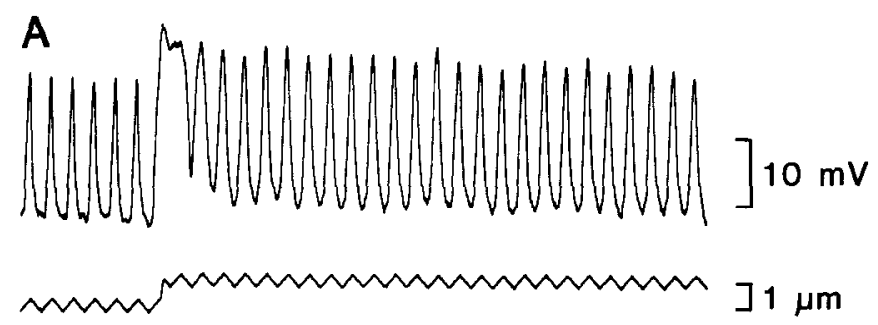

B


Figure 15. Changes in the intracellularly recorded responses to $20 \mathrm{~Hz}$ triangle-wave stimuli after the onset $(A)$ and termination $(B)$ of a 6.5 sec positive step. plitude even for displacements that evoked maximal responses. Figure 16, $A$ and $B$, shows the responses of a hair cell to 2 such step displacements, of different amplitudes but both saturatingly large, superimposed on a triangle-wave stimulus. Displacement-response curves generated from these responses (Fig. 16, $C, D)$ show that the curve shifted more rapidly and further along the displaccment axis during the larger stcp. For both steps, the shift reached a steady-state value equal to $95-100 \%$ of step amplitude within about $100 \mathrm{msec}$ of step onset. In contrast, the displacement shift in the cell of Figure 14 took 200 msec to reach a steady-state value that was $65 \%$ of step amplitude, illustrating the variability between cells.

In vitro receptor current. The similarity in the displacement shifts in the microphonic current and receptor potential preparations suggested that the displacement-shift process affects the receptor currents of individual hair cells. This was confirmed by recording receptor current in 6 voltage-clamped hair cells. All but one showed evidence of adaptation in the receptor current. Figure 17 shows the receptor current from one cell in response to negative steps (Fig. 17A) alternating with $30 \mathrm{~Hz}$ sinusoidal bursts (Fig. 17B). The negative step elicited a small, maintained reduction in inward current followed by a large, transient rebound at the termination of the step. The cell's displacement-response curve at the end of the step (measured from the rebound) was shifted negatively along the displacement axis relative to the unadapted displacement-response curve (measured from the response to the first cycle of the sinusoid; Fig. $17 \mathrm{C}$ ). The displacement-shift process thus continues to operate when the membrane potential is clamped near its resting value.

The positive displacement shift that occurred in the microphonic current preparation during symmetric stimuli (Fig. 10) was also seen in single cells. Comparison of the displacementresponse curves for the first 3 sinusoidal cycles in Figure $17 \mathrm{C}$ shows that the second and third curves were displaced positively relative to the first. Similar positive shifts were often seen when recording receptor potentials during triangle-wave or sinusoidal bursts of $10 \mathrm{~Hz}$ or more. After the first $50-100 \mathrm{msec}$ of a symmetrical stimulus, no further shift occurred, even for longer 
A

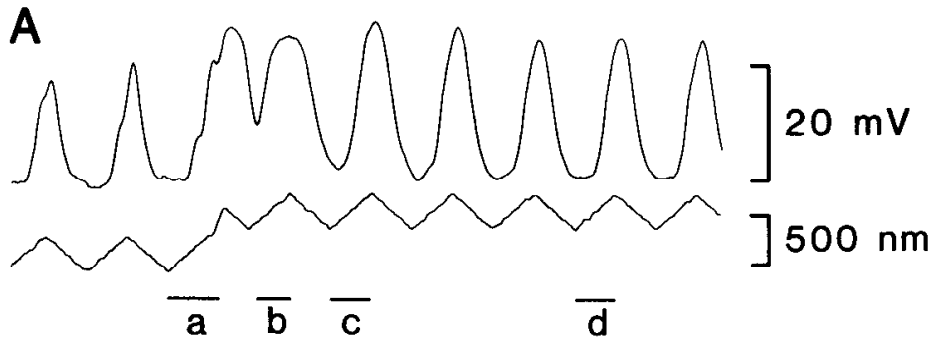

B





D



Figure 16. Displacement shifts in a hair cell's displacement-response curve during steps of different amplitude, rccorded intracellularly from the same cell shown in Figure 15. $A, B$, Receptor potentials and stimuli. $C, D$, Displacement-response curves generated from the data in $A$ and $B$ by the procedure of Figure 14. In each case, curve $a$ corresponds to the rise of the step. Curves $b-d$ correspond to successively later times. Arrowheads show the step displacements.

stimuli. The displacement-response curves returned to their original positions after a stimulus.

\section{Discussion}

Adaptation of saccular afferents

Sensitivity to linear acceleration has been found in otolithic afferents of many animals, including rays (Lowenstein and Roberts, 1960), frogs (Lowenstein and Saunders, 1975; Lewis et al., 1982), cats (Vidal et al., 1971; Loe et al., 1973), and monkeys (Fernandez and Goldberg, 1976a-c). Afferents from the goldfish's sacculus, whose primary function is thought to be auditory, are also sensitive to linear accelerations (Fay, 1984). All organisms experience linear accelerations from sources that include self-generated movement, substrate vibration, fluid motion, and gravity. According to the model of otolithic mechanics outlined in the introduction, the resting displacement of the otoconial mass parallel to the plane of the macula, and thus the amplitude of hair bundle deflection, is proportional to the component of gravity in that plane. This implies that otolithic organs are subject to stimuli of about $10 \mathrm{~m} / \mathrm{sec}^{2}$. At the same time, saccular afferents in frogs are exquisitely sensitive to substrate vibrations in the frequency range $20-300 \mathrm{~Hz}$, with thresholds as low as $100 \mu \mathrm{m} / \mathrm{sec}^{2}$ in the bullfrog (Koyama et al., 1982) and $10 \mu \mathrm{m} /$ $\mathrm{sec}^{2}$ in the white-lipped frog (Narins and Lewis, 1984). Our results indicate that saccular afferents adapt to static accelerations, such as gravity, in a way that restores their sensitivity to transient stimuli, such as vibrations.

The lime course of the in vivo adaptation indicates that the responses of the hair cells and neurons are high-pass-filtered, with a corner frequency in the range of 5-20 Hz. This observation is consistent with other studies. Lewis and co-workers (1982) characterized saccular afferents in the bullfrog as sensitive to substrate vibrations, and in some cases to auditory stimuli, at frequencies below $300 \mathrm{~Hz}$. In a subsequent study on the bullfrog's eighth nerve they found that vibration-sensitive afferents, presumably from the sacculus and lagena, were most sensitive at frequencies ranging from 20 to $150 \mathrm{~Hz}$ (Koyama et al., 1982). Lewis et al. (1982) found no gravitational sensitivity in saccular afferents. We anticipate that saccular afferents will be sensitive to changes in orientation with respect to gravity, but because of adaptation will not respond to stimuli below 5 $10 \mathrm{~Hz}$.

The adaptation of saccular neurons to constant accelerations is accompanied by the restoration of sensitivity to transient accelerations (Fig. 4). The results of experiments with test steps and adapting steps are consistent with a process that simply shifts the stimulus-response function of the neurons along the stimulus axis in the direction of the static stimulus. Such a process would, by itself, cause a response decay to a static stimulus, and has been identified in the saccular hair cells. However, it is possible that additional processes contribute to the adaptation of the neurons to an acceleration step. Because the rates of decay of spike probability, the averaged postsynaptic potentials, and microphonic potential are similar, any adaptation processes of importance must precede transmission at the afferent synapse. This localizes the adaptation to the hair cells or to their mechanical input. Whether adaptation occurs in the input is not known. A net displacement of the otoconial mass relative to the position of the macula is expected to persist for the duration of a maintained acceleration. In agreement with this, a study on the motion of the saccular otolith in a teleost fish found that centrifugal acceleration caused maintained displacement of the otolith relative to the macula (de Vries, 1950). In a scanning electron microscopic study, Hillman and Lewis (1971) found evidence that hair bundle displacements persist during static acceleration. When bullfrogs' sacculi were fixed in situ, the angular deflections of the hair bundles depended on whether the animals were prone or supine at the time of fixation. 

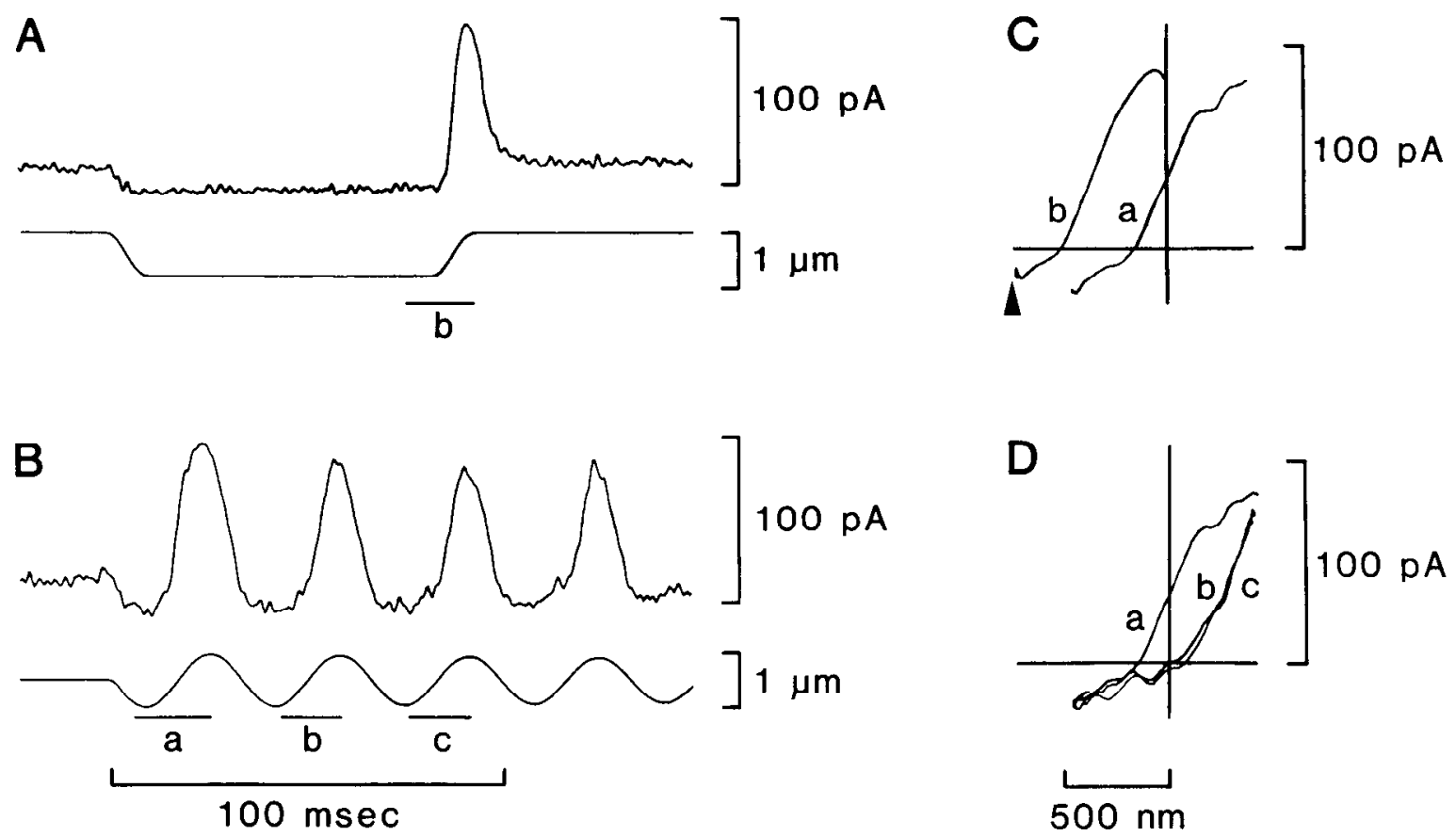

Figure 17. Displacement shifts in a voltage-clamped hair cell. Membrane potential was clamped at $-60 \mathrm{mV}$. The receptor current has been inverted to facilitate comparison with the receptor potential; inward, depolarizing, current is shown as upward. The stimuli were negative steps, alternating with sinusoidal bursts; the 2 kinds of stimuli were averaged separately in this figure. $A$. Inward current was reduced during a -750 nm step, and was followed by a large rebound at the step's termination. Average of 20 trials. $B$, Response to $150 \mathrm{msec}, 30 \mathrm{~Hz}$ sinusoidal burst. Average of 20 trials. $C, D$, Displacement-response curves generated from the data of $A$ and $B$ by the procedure of Figure 14. Curve $a$ in each case corresponds to the first positive-going half-cycle of the sinusoidal burst in $B$ and best represents the resting displacement-response curve of the cell. $C$, Curve $b$, generated from the rebound response at the offset of the negative step, indicates that during the negative step the curve shifted negatively along the displacement axis. $D$, Curves $b$ and $c$ demonstrate that the curve shifted positively along the displacement axis during the burst.

\section{Adaptation in hair cells}

While it remains possible that some adaptation occurs in the mechanical input to the hair cells in vivo, our in vitro experiments have shown that adaptation occurs in the hair cells. The microphonic current preparation showed that the hair cell responses adapt when the otoconial mass is removed and the otolithic membrane is directly displaced. The intracellular results were consistent with the microphonic current data, suggesting that the coupling between hair bundles and otolithic membrane is not a significant source of adaptation in this organ. The adaptive shift of the displacement-response curve proceeded when hair cells were clamped near resting potential, and so is not a consequence of the voltage change following stimulation. Moreover, the extent of adaptation does not depend in a simple fashion on current through the transduction channels (Fig. 12). These observations suggest that the displacement-shift process precedes transduction, i.e., it occurs either in the hair bundle or in its relation with the apical surface of the cell. The recent observation of time-dependent changes in hair bundle stiffness (Howard and Hudspeth, 1986) is also consistent with this conclusion. The decay in the receptor potential due to the displacement-shift process may, however, be augmented by the activation of voltage- and ion-sensitive conductances within the hair cell.

\section{Characteristics of the adaptive shift process in hair cells}

The process underlying the adaptive shift of the displacementresponse curve is nonlinear, occurring more rapidly for positive than for negative steps and more completely for small than for large steps. The process depends in a saturable way on extracellular $\mathrm{Ca}^{2+}$ and is inhibited by some other divalent cations; these observations suggest a specific site of action for $\mathrm{Ca}^{2+}$. The temperature dependence seems more consistent with an active, cell-mediated mechanism than with passive mechanical relaxation.

\section{Lability of hair cell adaptation}

Adaptation by saccular neurons in vivo and by saccular hair cells in vitro differs in reliability and rate. The neurons' responses and the microphonic potential in living animals adapt very consistently to excitatory steps of acceleration, always decaying to $10 \%$ or less of the peak response within $10-30$ msec. In contrast, the microphonic current during positive displacements of the otolithic membrane in vitro takes $100 \mathrm{msec}$ to decay to $10-30 \%$ of the initial response. Decay of the intracellular responses to positive hair bundle displacements is more variable, reaching a steady-state level that is $5-80 \%$ of the peak value in a time period varying from 10 (Fig. 17) to 200 (Fig. 14) msec. We can suggest 2 possible reasons for these discrepancies. First, as discussed above, there may be an additional, mechanical stage of adaptation in vivo that causes relaxation of the input to the hair bundles. Second, adaptation processes may occur more reliably in vivo. In the in vitro microphonic current preparation, the rate and extent of adaptation declined during the 10-20 hr of an experiment. During receptor potential recordings from single cells, both the response decay during a step and displacement shifts during steps and bursts gradually declined during 
the 5-60 min recording interval, leaving a nonadapting response. Deterioration was very rapid during voltage-clamp experiments, occurring within tens of seconds. Adaptation was totally lacking in tight-seal, whole-cell recordings from the same experimental preparation (Holton and Hudspeth, 1986). These observations suggest that the adaptation process is compromised in vitro, particularly by the invasive techniques of intracellular recording. They also indicate that the adaptation process is not essential for mechanoelectrical transduction per se and is more vulnerable to the experimental conditions than is transduction.

\section{Relation to adaptation in other hair cell organs}

Although adaptation is commonly observed in the responses of afferents from hair cell organs, we do not know whether the displacement-shift process occurs in other hair cells. Such a mechanism would seem most useful in organs like the frog's sacculus, in which hair cells are subject to static displacements that could potentially saturate their instantaneous displacement-response functions and thereby compromise their sensitivity to smaller displacements. In the auditory organs of mammals, reptiles, and birds, mechanical adaptation to static and very-low-frequency stimuli is accomplished by means of the helicotrcma, a channel linking the scala vestibuli and scala tympani. Even in auditory organs, however, a displacement-shift process in the hair cells might be useful in addition to macromechanical mechanisms, as it would tend to hold each cell in the sensitive region of its displacement-response function (Hudspeth, 1983). Although static hair bundle displacements have not been applied to hair cells in auditory organs, the effect of static displacement of the basilar membrane has been examined. Konishi and Nielsen (1978) plugged the helicotrema in the guinea pig's cochlea and applied trapezoidal displacements to the round window. The microphonic potential did not adapt during shortduration displacements, but did show some adaptation during displacements of $1 \mathrm{sec}$ or longer. Crawford and Fettiplace (1983) found that auditory afferents in the turtle adapted to maintained displacements of the basilar membrane, and suggested that the adaptation occurred either in the coupling between hair bundles and the tectorial membrane or in the hair cell response.

Asymmetry in the process that causes displacement shifts during steps may cause positive displacement shifts during symmetrical stimulation. In the intracellular experiments, the shift during symmetrical stimuli led to a small decrease in response (Fig. 17). The phase-locked responses of the bullfrog's saccular afferents also adapt within the first $100 \mathrm{msec}$ of a sinusoidal acceleration burst (R. A. Eatock, unpublished observations). This raises the possibility that a displacement-shift process in hair cells contributes to the well-documented adaptation of eighth-nerve afferents to sinusoidal stimuli. However, in the cochlear hair cells of turtles, alligator lizards, and mammals, receptor potentials do not appear to adapt to tone bursts (Fettiplace and Crawford, 1978; Holton and Weiss, 1983; Russell and Sellick, 1983; Smith et al., 1983).

In organs in which static sensitivity is desirable, such as those that provide tonic gravitational sensitivity, any adaptation process in the hair cells may be undesirable. In these cases, the displacement-shift process may not exist or may proceed at a very slow rate. The $\mathrm{Ca}^{2+}$ sensitivity of the adaptation process could provide a mechanism for regulating the rate of adaptation in different hair cell organs or even in different hair cells of the same organ.

\section{References}

Corey, D. P., and A. J. Hudspeth (1979a) Ionic basis of the receptor potential in a vertebrate hair cell. Nature 281: 675-677.

Corey, D. P., and A. J. Hudspeth (1979b) Response latency of vertebrate hair cells. Biophys. J. 26: 499-506.

Corey, D. P., and A. J. Hudspeth (1980) Mechanical stimulation and micromanipulation with piezoelectric bimorph elements. J. Neurosci. Methods 3: 183-202.

Corey, D. P., and A. J. Hudspeth (1983a) Analysis of the microphonic potential of the bullfrog's sacculus. J. Neurosci. 3: 942-961.

Corey, D. P., and A. J. Hudspeth (1983b) Kinetics of the receptor current in bullfrog saccular hair cells. J. Neurosci. 3: 962-976.

Crawford, A. C., and R. Fettiplace (1983) Auditory nerve responses to imposed displacements of the turtle basilar membrane. Hearing Res. 12: 199-208.

de Vries, H. L. (1950) The mechanics of the labyrinth otoliths. Acta Otolaryngol. 38: 262-273.

Eatock, R. A., and A. J. Hudspeth (1981) Adaptation in hair cells: In vitro responses and in vivo microphonic potentials from a vestibular organ. Soc. Neurosci. Abstr. 7: 62.

Eatock, R. A., D. P. Corey, and A. J. Hudspeth (1979) Adaptation in a vertebrate hair cell: Stimulus-induced shift of the operating range. Soc. Neurosci. Abstr. 5: 19.

Fay, R. R. (1984) The goldfish ear codes the axis of acoustic particle motion in three dimensions. Science 225: 951-954.

Fernandez, C., and J. M. Goldberg (1976a) Physiology of peripheral neurons innervating otolith organs of the squirrel monkey. I. Response to static tilts and to long-duration centrifugal force. $J$. Neurophysiol. 39: 970-984.

Fernandez, C., and J. M. Goldberg (1976b) Physiology of peripheral neurons innervating otolith organs of the squirrel monkey. II. Directional selectivity and force-response relations. J. Neurophysiol. 39. 985-995.

Fernandez, C., and J. M. Goldberg (1976c) Physiology of peripheral neurons innervating otolith organs of the squirrel monkey. III. Response dynamics. J. Neurophysiol. 39: 996-1008.

Fettiplace, R., and A. C. Crawford (1978) The coding of sound pressure and frequency in cochlear hair cells of the terrapin. Proc. R. Soc. Lond. [Biol.] 203: 209-218.

Flock, A. (1965) Electron microscopic and electrophysiological studies on the lateral line organ. Acta Otolaryngol. Suppl. 199: 1-90.

Furukawa, T., and S. Matsuura (1978) Adaptive rundown of excitatory postsynaptic potentials at synapses between hair cells and eighth nerve fibres in the goldfish. J. Physiol. (Lond.) 276: 193-209.

Furukawa, T., M. Kuno, and S. Matsuura (1982) Quantal analysis of a decremental response at hair cell-afferent fibre synapses in the goldfish sacculus. J. Physiol. (Lond.) 322: 181-195.

Goldberg, J. M., and C. Fernandez (1975) Vestibular mechanisms. Annu. Rev. Physiol. 37: 129-162.

Hillman, D. E. (1969) New ultrastructural findings regarding a vestibular ciliary apparatus and its possible functional significance. Brain Res. 13: 407-412.

Hillman, D. E., and E. R. Lewis (1971) Morphological basis for a mechanical linkage in otolithic receptor transduction in the frog. Science 174: 416-419.

Holton, T., and A. J. Hudspeth (1986) The transduction channel of hair cells from the bull-frog characterized by noise analysis. J. Physiol. (Lond.) 375: 195-227.

Holton, T., and T. F. Weiss (1983) Receptor potentials of lizard cochlear hair cells with free-standing stereocilia in response to tones. J. Physiol. (Lond.) 345: 205-240.

Howard, J., and A. J. Hudspeth (1986) Mechanical relaxation of the hair bundle correlates with adaptation in the mechanoelectrical transduction process of a hair cell. Soc. Neurosci. Abstr. 12: 778 .

Hudspeth, A. J. (1982) Extracellular current flow and the site of transduction by vertebrate hair cells. J. Neurosci. 2: 1-10.

Hudspeth, A. J. (1983) Transduction and tuning by vertebrate hair cells. Trends Neurosci. 6: 366-369.

Hudspeth, A. J., and D. P. Corey (1977) Sensitivity, polarity and conductance change in the response of vertebrate hair cells to controlled mechanical stimuli. Proc. Natl. Acad. Sci. USA 74: 24072411.

Hudspeth, A. J., and R. Jacobs (1979) Stereocilia mediate transduction in vertebrate hair cells. Proc. Natl. Acad. Sci. USA 76: 1506-1509. 
Konishi, T., and D. W. Nielsen (1978) The temporal relationship between basilar membrane motion and nerve impulse initiation in auditory nerve fibres of guinea pigs. Jpn. J. Physiol. 28: 291-307.

Koyama, H., E. R. Lewis, E. L. Leverenz, and R. A. Baird (1982) Acute seismic sensitivity in the bullfrog ear. Brain Res. 250: 168172.

Kuno, M. (1983) Adaptive changes in firing rates in goldfish auditory fibers as related to changes in mean amplitude of excitatory postsynaptic potentials. J. Neurophysiol. 50: 573-581.

Lewis, R. S., and A. J. Hudspeth (1983) Voltage- and ion-dependent conductances in solitary vertebrate hair cells. Nature 304: 538-541.

Lewis, E. R., R. A. Baird, E. L. Leverenz, and H. Koyama (1982) Inner ear: Dye injection reveals peripheral origins of specific sensitivities. Science 215: 1641-1643.

Loe, P. R., D. L. Tomko, and G. Werner (1973) The neural signal of angular head position in primary afferent vestibular nerve axons. J. Physiol. (Lond.) 230: 29-50.

Lowenstein, O., and T. D. M. Roberts (1950) The equilibrium function of the otolith organs of the thornback ray (Raja clavata). J. Physiol. (Lond.) 110: 392-415.

Lowenstein, O., and R. D. Saunders (1975) Otolith-controlled responses from the first-order neurons of the labyrinth of the bullfrog (Rana catesbeiana) to changes in linear acceleration. Proc. R. Soc. Lond. [Biol.] 191: 475-505.
Narins, P. M., and E. R. Lewis (1984) The vertebrate ear as an exquisite seismic sensor. J. Acoust. Soc. Am. 76: 1384-1387.

Ohmori, H. (1985) Mechano-electric transduction currents in isolated vestibular hair cells of the chick. J. Physiol. (Lond.) 359: 189-217.

Rossi, M. L., P. Valli, and C. Casella (1977) Post-synaptic potentials recorded from afferent nerve fibres of the posterior semicircular canal in the frog. Brain Res. 135: 67-75.

Russell, I. J., and P. M. Sellick (1983) Low-frequency characteristics of intracellularly-recorded receptor potentials in guinea-pig cochlear hair cells. J. Physiol. (Lond.) 338: 179-206.

Sand, O. (1975) Effects of different ionic environments on the mechanosensitivity of lateral line organs in the mudpuppy. J. Comp. Physiol. 102: $27-42$.

Schessel, D. A., and S. M. Highstein (1981) Is transmission between the vestibular type I hair cell and its primary afferent chemical? Ann. NY Acad. Sci. 374: 210-214.

Smith, R. L., M. L. Brachman, and D. A. Goodman (1983) Adaptation in the auditory periphery. Ann. NY Acad. Sci. 405: 79-93.

Vidal, J., M. Jeannerod, W. Lifschitz, H. Levitan, J. Rosenberg, and J. P. Segundo (1971) Static and dynamic properties of gravity-sensitive receptors in the cat vestibular system. Kybernetik 9: 205-215.

Young, L. R. (1969) The current status of vestibular system models. Automatica 5: 369-383. 